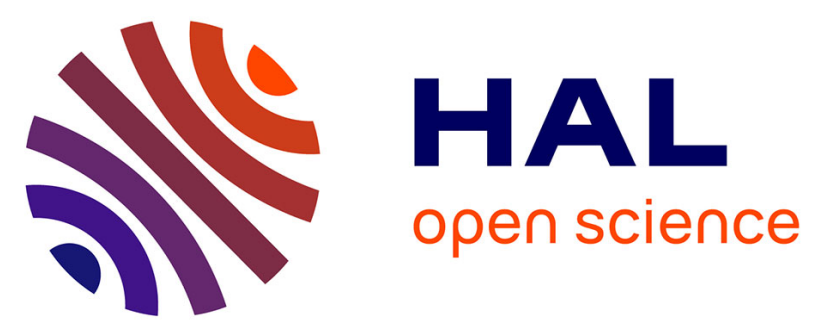

\title{
Chains of magnetosomes with controlled endotoxin release and partial tumor occupation induce full destruction of intracranial U87-Luc glioma in mice under the application of an alternating magnetic field
}

Edouard Alphandéry, Ahmed Idbaih, Clovis Adam, Jean-Yves Delattre, Charlotte Schmitt, François Guyot, Imène Chebbi

\section{To cite this version:}

Edouard Alphandéry, Ahmed Idbaih, Clovis Adam, Jean-Yves Delattre, Charlotte Schmitt, et al.. Chains of magnetosomes with controlled endotoxin release and partial tumor occupation induce full destruction of intracranial U87-Luc glioma in mice under the application of an alternating magnetic field. Journal of Controlled Release, 2017, 10.1016/j.jconrel.2017.07.020 . hal-01565231

\section{HAL Id: hal-01565231 \\ https://hal.sorbonne-universite.fr/hal-01565231}

Submitted on 19 Jul 2017

HAL is a multi-disciplinary open access archive for the deposit and dissemination of scientific research documents, whether they are published or not. The documents may come from teaching and research institutions in France or abroad, or from public or private research centers.
L'archive ouverte pluridisciplinaire HAL, est destinée au dépôt et à la diffusion de documents scientifiques de niveau recherche, publiés ou non, émanant des établissements d'enseignement et de recherche français ou étrangers, des laboratoires publics ou privés. 
1 Chains of magnetosomes with controlled endotoxin release and partial 2 tumor occupation induce full destruction of intracranial U87-Luc glioma 3 in mice under the application of an alternating magnetic field.

4 Edouard Alphandéry a,b, , Ahmed Idbaih ' ${ }^{c}$, Clovis Adam ', Jean-Yves Delattre ${ }^{c}$, Charlotte Schmitt ${ }^{c}$, 5 François Guyot $^{a}$, Imène Chebbi ${ }^{b}$.

7 a Institut de minéralogie, de physique des matériaux et de cosmochimie, UMR 7590 CNRS, Sorbonne 8 Universités, UPMC, University Paris 06, Muséum National d'Histoire Naturelle, 4 Place Jussieu, 75005, 9 Paris, France.

$10 \quad{ }^{b}$ Nanobacterie SARL, 36 boulevard Flandrin, 75016, Paris, France.

$11{ }^{\mathrm{c}}$ Inserm U 1127, CNRS UMR 7225, Sorbonne Universités, UPMC, University Paris 06, UMR S 1127, 12 Institut du Cerveau et de la Moelle épinière, ICM, F-75013, Paris, France.

13 AP-HP, Hôpitaux Universitaires Pitié Salpêtrière - Charles Foix, Service de Neurologie 2-Mazarin, F14 75013, Paris, France.

$15{ }^{\mathrm{d}}$ Laboratoire de neuropathologie, GHU Paris-Sud-Hôpital Bicêtre, 78 rue du Général Leclerc, 94270 Le 16 Kremlin Bicêtre, France.

$18 *$ Corresponding author Email address:

19 edouardalphandery@hotmail.com 
24 Previous studies have shown that magnetic hyperthermia could efficiently destroy tumors both

25 preclinically and clinically, especially glioma. However, antitumor efficacy remained suboptimal and

26 therefore required further improvements. Here, we introduce a new type of nanoparticle synthesized by

27 magnetotactic bacteria called magnetosomes with improved properties compared with commonly used

28 chemically synthesized nanoparticles. Indeed, mice bearing intracranial U87-Luc glioma tumors injected

29 with $13 \mu \mathrm{g}$ of nanoparticles per $\mathrm{mm}^{3}$ of tumor followed by 12 to 15 of 30 minutes alternating magnetic

30 field application displayed either full tumor disappearance (40\% of mice) or no tumor regression using

31 magnetosomes or chemically synthesized nanoparticles, respectively. Magnetosome superior antitumor

32 activity could be explained both by the increased production of heat and by endotoxin release under the

33 alternating magnetic field application. Most interestingly, this behavior was observed when

34 magnetosomes occupied only $10 \%$ of the tumor volume, which suggests that an indirect mechanism,

35 such as an immune activity, is involved in tumor regression. This is desired for the treatment of

36 infiltrating tumors, such as glioma, for which whole tumor coverage by nanoparticles can hardly be 37 achieved.

40 KEYWORDS

41 Magnetosomes, magnetotactic bacteria, magnetic hyperthermia, alternating magnetic field, glioblastoma. 


\section{1. INTRODUCTION}

48 A series of different nanotechnologies, such as lipid-based nanoformulations, polymer-drug conjugates,

49 recombinant viruses, metallic nanoparticles, drug-targeted antibodies, and herbal nanoparticles, have

50 been successfully developed for cancer treatment both at fundamental and industrial levels (1). Among

51 them, technologies in which nanoparticle anti-tumor activity can be controlled by applying an external

52 source of energy, such as a laser (2), (3), radiation (4), (5), ultrasound (6), (7), or magnetic field (8), (9)

53 appear promising because they can potentially enhance both treatment safety and efficacy. Strategies to

54 increase nanoparticle SAR by combining magnetic hyperthermia with photothermia using magneto-

55 plasmonic nanohybrids have also been suggested (10), (11). There is interest in developing this type

56 of nanotechnology for glioblastoma (GBM) treatment, especially for the most severe GBM cases, which

57 are non-operable. With the current standard of care, i.e., maximal safe surgery, concurrent

58 radiochemotherapy and adjuvant chemotherapy, GBM, which affects 25,000 patients per year in the

59 United States and Europe (12), (13), remains incurable with a poor prognosis. The five-year survival

60 time of patients with GBM is low at 10\% (14), (15), demonstrating the need for new treatment

61 options (16), (17), (18), (19), (20). Among the potential treatments for GBM are different types

62 of nanothermotherapies (21), such as photodynamic therapy (22) and magnetic hyperthermia, which

63 have been tested to treat GBM (9). Compared with other thermotherapies, magnetic hyperthermia (23),

64 (24), (25), (26), (27), in which tumors are typically heated to $43-50{ }^{\circ} \mathrm{C}$ by intratumor

65 administration of iron oxide nanoparticles followed by alternating magnetic field (AMF) application,

66 appears promising. This is due to more localized heat produced by the nanoparticles, which results in

67 enhanced efficacy, and to tumor destruction achieved at lower temperatures, which strengthens

68 treatment safety. In a clinical trial that enrolled 14 patients with GBM, magnetic hyperthermia treatment

69 performed using small chemically synthesized iron oxide nanoparticles (IONP) was well-tolerated by 
70 patients, did not produce major side effects, and led to an increased survival time of 7 months compared

71 with conventional treatments (28), (29).

72 Treatment efficacy could potentially be further improved by using chains of magnetosomes (CM), which

73 are iron oxide nanoparticles synthesized by magnetotactic bacteria, instead of IONP. In previous studies,

74 CMs have been shown to destroy MDA-MB-231 breast tumors subcutaneously xenografted under the

75 skin of mice more efficiently than IONPs (30), (31). Magnetosome efficacy was attributed to the

76 large magnetosome size, leading to stable ferrimagnetic properties and to a large amount of heat

77 produced under AMF application, as well as to an arrangement of chains that prevented aggregation and

78 promoted homogenous magnetosome distribution in the tumor (32), (33), (34), (35).

79 In the present study, anti-tumor activity against U-87-Luc GBM was studied both in vitro and in vivo

80 with a suspension containing CMs. We first demonstrated that the amount of endotoxins released from

81 the CMs can be controlled under AMF applications. CM cytotoxicity and internalization properties in

82 the presence of U87-Luc cells were also studied in vitro. Mice bearing intracranial U87-Luc tumors

83 were then treated under conditions that could be followed clinically, i.e., using an AMF with $30 \mathrm{mT}$ and

$84198 \mathrm{kHz}\left(\mathrm{H} . \mathrm{f}=810^{8} \mathrm{~A} \cdot \mathrm{m}^{-1} \cdot \mathrm{s}^{-1}\right.$, below the threshold of $5.10^{9} \mathrm{~A} \cdot \mathrm{m}^{-1} \cdot \mathrm{s}^{-1}$, above which Eddy currents may

85 occur) (26), (36). Treatment parameters, such as the number of magnetic sessions and quantity of

86 CMs administered, that lead to complete disappearance of the intracranial U87-Luc tumors were

87 determined and compared with IONP treatment, which has been previously used to perform preclinical

88 magnetic hyperthermia tumor treatments (37), (38). During the various treatments, nanoparticle

89 distribution in the tumors and the presence of different cell types in the brain were also examined by

90 histology. This study also suggests a mechanism for tumor destruction and verified that the brain tumor

91 disappeared fully following magnetic hyperthermia treatment with CMs.

92 2. MATERIALS AND METHODS 
Magnetospirillum magneticum AMB-1 magnetotactic bacteria at biosafety level 1 were purchased from

ATCC (79024 strain). Five milliliters of a suspension containing $4.10^{6}$ of these bacteria per milliliter

were introduced into one liter of sterile 1653 ATCC culture medium containing nutrients and additives, such as minerals, vitamins, and an iron source, as listed in the 1653 ATCC medium, which is required oxygen concentration in the growth medium, which would prevent magnetosome production. The media

101 containing the bacteria were then placed in an incubator at $30^{\circ} \mathrm{C}$ for 7 days to enable bacterial growth

102 and magnetosome production. After 7 days, the media was centrifuged at $4000 \mathrm{~g}$ for 45 minutes. The

103 bacterial pellet was washed using $1 \mathrm{ml}$ of sterile water (Millipore ${ }^{\circledR}$ ). Magnetotactic bacteria were

104 concentrated using a strong Neodinium magnet (0.6 Tesla), re-suspended in 0.05 M TRIS and sonicated

105 with a sonicating finger at $0{ }^{\circ} \mathrm{C}$ for 2 hours at $30 \mathrm{~W}$. The suspension containing the chains of

106 magnetosomes extracted from the magnetotactic bacteria was washed several times with sterile water

107 using a magnet to isolate the CMs from the supernatant containing cellular debris and residual bacteria

108 until the cellular debris disappeared from the supernatant. Sonication was performed at $30 \mathrm{~W}$ by a series

109 of three 2-second pulses between each wash. The CMs were then re-suspended in $1 \mathrm{ml}$ of sterile water.

110 For the intracranial injections, the CMs were re-suspended in a sterile injectable solution containing 5\%

111 glucose and exposed to ultraviolet lamp (UV) irradiation for $12 \mathrm{~h}$ for partial sterilization.

112 2.2. Preparation of IONPs:

113 IONPs, which are starch-coated iron oxide nanoparticles, were purchased from Micromod

114 Partikeltechnologie GmbH company, Friedrich-Barnewitz-Str. 4, D-18119, Rostock, Germany (ref: 10115 00-102).

\section{2.3. Nanoparticle Characterization:}

117 Nanoparticle sizes, shapes, and organization were determined using a transmission electron microscope 118 (JEM-2100, JEOL, Japan). The iron concentrations of the different nanoparticle suspensions were 119 measured by mixing these suspensions with hydrochloric acid and hydrogen peroxide to produce $\mathrm{Fe}^{3+}$ 
120 ions complexed with potassium thiocyanate, and total iron was then determined via an absorbance

121 measurement at $476 \mathrm{~nm}$. The concentrations were expressed as $\mathrm{mg}$ of maghemite contained in the CMs

122 and IONPs per $\mathrm{ml}$ of suspension or per $\mathrm{mm}^{3}$ of tumor. The zeta potentials of the different nanoparticles

123 in suspension were measured by dynamic light scattering (DLS, ZEN 3600, Malvern Instruments, UK).

124 The stability of the nanoparticle suspensions was estimated by measuring the changes in the optical

125 densities of these suspensions, which were measured at $476 \mathrm{~nm}$ for $15 \mathrm{~min}$. Nanoparticle FTIR spectra

126 were recorded with a FTIR spectrometer (Vertex 70, Bruker, USA). The amount of organic material at

127 the nanoparticle surface was measured using an elemental CHNS analyzer (Flash EA 1112, Thermo

128 Fisher Scientific, USA). More details about each of these techniques are provided in the supplementary

129 materials section.

\subsection{Set-up for generating the alternating magnetic field and for measuring the temperature}

131 We used an induction system operating at $198 \mathrm{kHz}$ to generate the alternating magnetic field. Mice,

132 Eppendorf tubes, petri dishes containing nanoparticles and possibly cells were inserted into a coil with a

133 7-cm diameter with four spires to generate a magnetic field with an average strength of $30 \mathrm{mT}$. We used

134 an infrared camera (EasIR-2, Optophase, France) positioned $20 \mathrm{~cm}$ above the coil to measure the

135 temperature both in vitro and in vivo. We verified the temperature with a thermocouple positioned at the

136 tumor center and that the infrared camera measured the temperature at the tumor center. This was

137 possible due to the shallowness of the tumor.

\subsection{Amount of endotoxins released under AMF application}

139 Suspensions containing $2 \mu \mathrm{l}$ of CMs or IONPs at a concentration of $20 \mathrm{mg} / \mathrm{ml}$ in iron oxide were treated

140 as follows. Nanoparticle suspensions were exposed to 0, 1, 2, 3, and 4 magnetic sessions, during which

141 an AMF of $198 \mathrm{kHz}$ and average strength of $30 \mathrm{mT}$ was applied for 30 minutes. After AMF

142 applications, $100 \mu \mathrm{l}$ of nonpyrogenic water was added to the suspensions, and the suspensions were

143 mixed for one minute and centrifuged at 13000 rotations per minute for 15 minutes. The endotoxin

144 concentration of the supernatant was measured using the Limulus amebocyte lysate (LAL) assay.

\section{$145 \quad$ 2.6. Materials and cells culture}


146 U87-MG Luc human GBM cell lines, which were transduced with a luciferase gene, were obtained from

147 Keith Ligon's lab and used in this study. After thawing, the U87-MG Luc adherent cells were cultivated

148 at $37{ }^{\circ} \mathrm{C}$ in the presence of $5 \% \mathrm{CO}_{2}$ in Dulbecco's Modified Eagle Medium (DMEM) containing $10 \%$

149 fetal bovine serum (FBS). Once the cells reached confluence, the culture dishes were rinsed with Hank's

150 Balanced Salt Solution (HBSS). The cells were then detached with trypsinization for 5 minutes at $37^{\circ} \mathrm{C}$

151 in the presence of $5 \% \mathrm{CO}_{2}$. The trypsin activity was stopped by the addition of medium containing FBS.

152 The cellular concentration was then determined using a Malassez cell.

\section{2.7. U87-Luc cytotoxicity in the absence of AMF using an MTT assay}

154 U87-Luc cytotoxicity studies were evaluated using an MTT assay. This technique measures the ability of

155 mitochondrial enzymes to reduce 3-(4,5-dimethylthiazol-2-yl)-2,5-diphenyltetrazolium bromide to

156 purple formazan crystals. Cells were seeded at a density of $10^{4}$ cells per well in 96 -well flat-bottom

157 plates and incubated in completed culture medium for $24 \mathrm{~h}$. Then, the U87-Luc cell medium was

158 removed and replaced with 10\% FCS-medium containing CMs or IONPs at varying concentrations

159 ranging from $7.8 \mu \mathrm{g} / \mathrm{ml}$ to $1000 \mu \mathrm{g} / \mathrm{ml}$ in maghemite. After $24 \mathrm{~h}$ of incubation, the cells were washed

160 with HBSS and incubated with $0.1 \mathrm{ml}$ of MTT $(2 \mathrm{mg} / \mathrm{ml})$ for an additional $4 \mathrm{~h}$ at $37{ }^{\circ} \mathrm{C}$. The insoluble

161 product was then dissolved by the addition of $100 \mathrm{ml}$ of isopropanol. The absorbance corresponding to

162 the solubilized formazan pellets, which reflect the relative viable cell numbers, was measured at $540 \mathrm{~nm}$

163 using a microplate reader. We measured the absorbance at $540 \mathrm{~nm}$ for the cells with the nanoparticles

164 without formazan blue and we have subtracted this signal from the signal for the cells with nanoparticles

165 with formazan blue. The percent inhibition of cell proliferation, inhibition (\%), was then estimated using

166 the following formula: $\%$ inhibition $=\left[1-\left(\mathrm{OD}_{\mathrm{TC}} / \mathrm{OD}_{\mathrm{UC}}\right)\right] \times 100$, where $\mathrm{OD}_{\mathrm{UC}}$ is the optical density of the

167 suspension of untreated cell, i.e., cells that have been washed with PBS and have not been in the

168 presence of nanoparticles, measured at $540 \mathrm{~nm}$, and $\mathrm{OD}_{\mathrm{TC}}$ is the optical density of the suspension of

169 treated cells, i.e., nanoparticle suspensions that have been added to cells, measured at $540 \mathrm{~nm}$. The

170 percent inhibition of cell proliferation was plotted as a function of the nanoparticle concentration. The

171 experiments were performed in triplicate. 
173 A total of 500,000 U87-Luc cells were seeded in a Petri dish (35 mm) for 24 hours. Then, $2 \mathrm{ml}$ of IONP

174 and CM suspensions were added to the cells at different concentrations varying between $1 \mathrm{mg} / \mathrm{ml}, \mathrm{which}$

175 is sufficient to induce an increase in temperature increase, and $40 \mu \mathrm{g} / \mathrm{ml}$, which corresponds to the

176 maximum magnetosome concentration in the tumor, i.e., $40 \mu \mathrm{g}$ of magnetosomes per $\mathrm{mm}^{3}$ of tumor.

177 When the same amount of nanoparticles used, we observed an increase in the temperature in solution

178 but not in vitro, possibly due to the lower concentrations in vitro $(2 \mathrm{ml}$ at $20 \mu \mathrm{g} / \mathrm{ml})$ than in solution (2

$179 \mu \mathrm{l}$ at $20 \mathrm{mg} / \mathrm{ml}$ ). Next, these assemblies were exposed (or not) to a $30 \mathrm{mT}$ and $198 \mathrm{kHz}$ AMF for 30

180 minutes. The cells were then incubated with the nanoparticles for $24 \mathrm{~h}$. The nanoparticle media was

181 removed, and the cells were washed twice with cold PBS. We verified that there were no observable

182 nanoparticle aggregates at the cell surface and that the nanoparticles were mostly internalized in cells by

183 optical microcopy. It is possible that nanoparticles that were not observed with the optical microscope

184 remained at cell surface, meaning that the measurement provides an estimate of the maximum quantity

185 of internalized nanoparticles or the amount of nanoparticles internalized in cells or at the cell surface.

186 Next, $250 \mu$ l of trypsin were added to detach the cells, and then the culture media was mixed with cells.

187 Following this in vitro treatment, the mixtures were centrifuged at $800 \mathrm{rpm}$ for 7 minutes. The

188 supernatant was removed and replaced with $100 \mu 1$ of annexin-binding buffer, $5 \mu 1$ of Alexa Fluor 488

189 Annexin $\mathrm{V}$ for early apoptosis detection, and $1 \mu \mathrm{l}$ of propidium iodide at $100 \mu \mathrm{g} / \mathrm{ml}$ for late apoptosis

190 and necrosis detection. The mixtures were incubated at room temperature for 15 minutes. Then, $400 \mu 1$

191 of annexin-binding buffer was added to this cell suspension and mixed gently. Ten microliters of this

192 suspension were loaded into the sample slide and were inserted completely into a Countess ${ }^{\mathrm{TM}}$ II FL

193 Automated Cell Counter (Thermo Fisher scientific), which was able to detect the Annexin and

194 Propidium Iodide emissions. The percentages of necrotic and apoptotic cells were thus obtained.

\section{2.9. Internalization of nanoparticles}

196 Following the in vitro treatments described in 2.7, the different mixtures were loaded into the sample 197 slide and completely inserted into a Countess ${ }^{\mathrm{TM}}$ II FL Automated Cell Counter to count the cells. The 
198 mixtures were then centrifuged, and the supernatant was removed and replaced with $286 \mu 1$ of $\mathrm{HNO}_{3}$

199 (70\%); the resulting treated mixtures were maintained at $4{ }^{\circ} \mathrm{C}$ for $24 \mathrm{~h}$ to lyse cells and dissolve the

200 nanoparticles into free iron. Finally, $10 \mathrm{ml}$ of filtered water was added to all the treated mixtures and the

201 iron concentration was then determined using ICP-AES measurements. We deduced the average

202 quantity of iron coming from the nanoparticles, which was internalized in each cell.

$203 \quad$ 2.10. In vivo experiments

204 In vivo experiments were performed following ethical guidelines and surgery was performed following

205 the guidelines of the Institutional Animal Care and Use Committee ("Ethic committee Charles Darwin $206 \mathrm{~N}^{\circ}$ 5”, project ethic number: 00764.03). Mice were fed and watered according to these guidelines and 207 euthanized by cervical dislocation when their weights had decreased by more than $20 \%$ or when signs of 208 pain, unusual posture or prostration were observed. At day 0 (D0), a cell suspension containing 10 $0^{5}$ 87209 Luc cells per microliter was first inoculated into the brains of 7-week-old CD-1 female nude mice with a 210 mean weight of $20 \mathrm{~g}$ from Charles River. To achieve the surgical procedure leading to cell implantation, 211 the mice were first anesthetized with a mixture of ketamine $(100 \mathrm{mg} / \mathrm{kg})$ and xylazine $(8 \mathrm{mg} / \mathrm{kg}) . \mathrm{The}$ 212 mouse head was then fixed in a stereotactic frame, a craniotomy was performed at the fixed coordinates $213(0.2 .0)$ and $2 \mu \mathrm{l}$ of a suspension containing $2.10^{5}$ U87-Luc cells were injected at the coordinates (0.2.2).

214 Tumors grew for 8 days between D0 and D8. At D8, 7 different groups containing 10 mice each were 215 treated as follows (Table S1(a)):

$216-\quad$ Group 1 received a $30 \mathrm{~mm}^{3} \mathrm{GBM}$ at coordinates $(0.2 .2) \mathrm{mm}$ and $2 \mu \mathrm{l}$ of an isotonic solution 217 containing 5\% glucose without any further treatment;

218 - $\quad$ Group 2 received a $5 \mathrm{~mm}^{3} \mathrm{GBM}$ at coordinates $(0.2 .2) \mathrm{mm}$ and the same glucose solution as

219 Group 1, followed by magnetic treatment consisting in 12 magnetic sessions (S) on D8 (S1), D9 (S2), 220 D10 (S3), D15 (S4), D16 (S5), D17 (S6), D22 (S7), D23 (S8), D24 (S9), D29 (S10), D30 (S11), and 221 D31 (S12);

222 - Group 3 received a $3 \mathrm{~mm}^{3} \mathrm{GBM}$ at coordinates (0.2.2) $\mathrm{mm}$ and a suspension containing $40 \mu \mathrm{g}$ of 223 magnetosome chains in maghemite without any further treatment; 
224 - $\quad$ Group 4 received a $3 \mathrm{~mm}^{3} \mathrm{GBM}$ at coordinates (0.2.2) $\mathrm{mm}$ and the same suspension as Group 3,

225 followed by magnetic treatment consisting in 15 magnetic sessions on D8 (S1), D9 (S2), D10 (S3), D15

226 (S4), D16 (S5), D17 (S6), D22 (S7), D23 (S8), D24 (S9), D29 (S10), D30 (S11), D31 (S12), D36 (S13),

227 D37 (S14), and D38 (S15);

228 - Group 5 received a $25 \mathrm{~mm}^{3} \mathrm{GBM}$ at coordinates (0.2.2) $\mathrm{mm}$ and the same suspension as group 3,

229 followed by 15 magnetic sessions on D8 (S1), D9 (S2), D10 (S3), D15 (S4), D16 (S5), D17 (S6), D22

230 (S7), D23 (S8), D24 (S9), D29 (S10), D30 (S11), D31 (S12), D36 (S13), D37 (S14), and D38 (S15);

231 - $\quad$ Group 6 received a $5 \mathrm{~mm}^{3} \mathrm{GBM}$ at coordinates (0.2.2) $\mathrm{mm}$ and $40 \mu \mathrm{g}$ of IONPs in maghemite

232 without any further treatment; and

233 - Group 7 received in a $3 \mathrm{~mm}^{3} \mathrm{GBM}$ at coordinates (0.2.2) $\mathrm{mm}$ and the same suspension as Group

234 6, followed by 12 magnetic sessions on D8 (S1), D9 (S2), D10 (S3), D15 (S4), D16 (S5), D17 (S6), D22

235 (S7), D23 (S8), D24 (S9), D29 (S10), D30 (S11), and D31 (S12).

236 For the different groups of mice, the bioluminescence intensity emitted by the living tumor cells was

237 measured on D7, D14, D21, D28, D35, D42, D49, D56 and D150.

238 During each magnetic session (S1 to S15), the mice were exposed to an AMF at an average strength of

$23930 \mathrm{mT}$ and a frequency of $198 \mathrm{kHz}$ that was applied for 30 minutes.

$240 \quad$ 2.11. Bioluminescence intensity and tumor volume measurements

241 The mice were first anesthetized using isoflurane. The bioluminescence intensity was then measured

242 using an IVIS Spectrum “In Vivo Imaging System” (PerkinElmer, Inc.) 10 minutes after intraperitoneal

243 injection of $100 \mathrm{mg} / \mathrm{kg}$ of beetle luciferin potassium salt (Promega: E1605) in PBS, which reacts with

244 luciferase to produce luminescent oxo-luciferin, (39), (40), (41). Images were analyzed with the

245 living Image 4.0 software from Caliper, Life Sciences. The bioluminescence intensity at the tumor site

246 was divided by the bioluminescence intensity measured in the flanks to remove the mouse auto-

247 luminescence signal. Then, the relationship between tumor bioluminescence intensity and tumor volume

248 was determined. For that, bioluminescence intensities were measured at D7, D14, D21, D28 and D35 in

249 a series of living mice. The tumor volumes were deduced from surface measurements of several 
250 horizontal histological sections positioned at various tumor heights, which were collected from mice

251 euthanized on the same day at the BLI measurements. A linear relationship was observed between the

252 logarithm of tumor bioluminescence intensity (BLI), $\log (\mathrm{BLI})$, and the logarithm of the tumor volume

253 expressed in $\mathrm{mm}^{3}, \log \left(\operatorname{volume}\left(\mathrm{mm}^{3}\right)\right)($ Fig. S3). A linear coefficient of 1.4 was deduced by fitting the

254 plot in Fig. S3 with a linear function, a value that agrees with previously reported values (40), (42), $255(43),(44)$

\subsection{Representation of tumor volume variations and estimates of survival time}

257 The variations in tumor volume in time were represented in Tukey diagrams using the Kaleida Graph 2584.03 software. Mouse survival times are plotted using the Kaplan-Meier model method (45), (46).

259 The statistical significance of the survival time between the different groups was evaluated using the log 260 rank test. Parameters are expressed as the median with p-values (9).

$261 \quad$ 2.13. Temperature measurements

262 Intratumor temperatures were measured as a function of time during the various treatments in living 263 mice using an infrared camera (EasIRTM ${ }^{-2}$, Optophase) placed $20 \mathrm{~cm}$ above the coil.

\section{2.14. Histological analysis}

265 Histological studies were performed on extracted brains that were fixed with a $4 \%$ solution of 266 formaldehyde for 24 hours, cut into $2-\mathrm{mm}$ thickness transverse slices, washed in an ethanol (70\%) bath 267 for 12 hours and included in paraffin. Sections of paraffin blocks with a thickness of $4 \mu \mathrm{m}$ were 268 deposited on glass slides and stained with hematoxylin-eosin (H\&E) and/or Prussian blue to distinguish 269 between healthy and tumor areas and to determine the location of the magnetosomes, polynuclear 270 neutrophils (PNN), and tumor and healthy cells. Histological analysis was also performed on the mice 271 that received glucose on day 8 and were euthanized 6 or 24 hours following glucose injection (Figs. 272 S5(a) and S5(c)). Six mice were analyzed at various times, including after 1 magnetic session 273 (Figs. S5(b)) or 24 hours after 3 magnetic sessions (Fig. S5(d)), in which they received CM on day 8 and 274 were euthanized 4 hours (Figs. 9(a) and 9(c)) or 72 hours (Figs. 9(b) and 9(d)) after the CM injection; 275 just after or 4 hours after 1 magnetic session (Figs. 8(a), 8(b) and 8(c)); and 24 hours after 3 magnetic 
276 sessions ( $=72$ hours, Figs. $8(\mathrm{~d})$ to $8(\mathrm{~g})$ ), in which they received IONPs on day 8 and were euthanized 6

277 or 72 hours after IONP administration (Figs. S4(a) and S4(c)) or 24 hours after 3 magnetic sessions (72

278 hours (Figs. S4(b) and S4(d)).

279

280

281

282

283

284

285

286

287

288

\section{RESULTS AND DISCUSSION}

\subsection{Properties of CMs and IONPs used for the tumor magnetic hyperthermia treatments}

CMs were extracted from AMB-1 whole magnetotactic bacteria, a species of bacteria that produces chains of nanoparticles called magnetosomes, as shown in the TEM image of a typical magnetotactic bacterium presented in Figure 1(a). After extraction from the magnetotactic bacteria, the magnetosomes maintain their organization in chains (Figure 1(b)), a type of organization that is advantageous for the treatment because it prevents aggregation and promotes uniform distribution and homogenous heat production. Magnetosomes appear to possess a cubooctahedric geometry, more uniform sizes and shapes than IONPs (Figs. S7(a) and S7(b)), a size that is larger than $20 \mathrm{~nm}$ for the majority of them and a mean size of $\sim 45 \mathrm{~nm}$ (Fig. S1(a)), which leads to a coercivity $\mathrm{H}_{\mathrm{c}}$ of $\sim 200-300$ Oe and a ratio between remnants and saturating magnetization of $\mathrm{Mr} / \mathrm{Ms} \sim 0.35$ at physiological temperature (Fig. S6), ( 47 ).

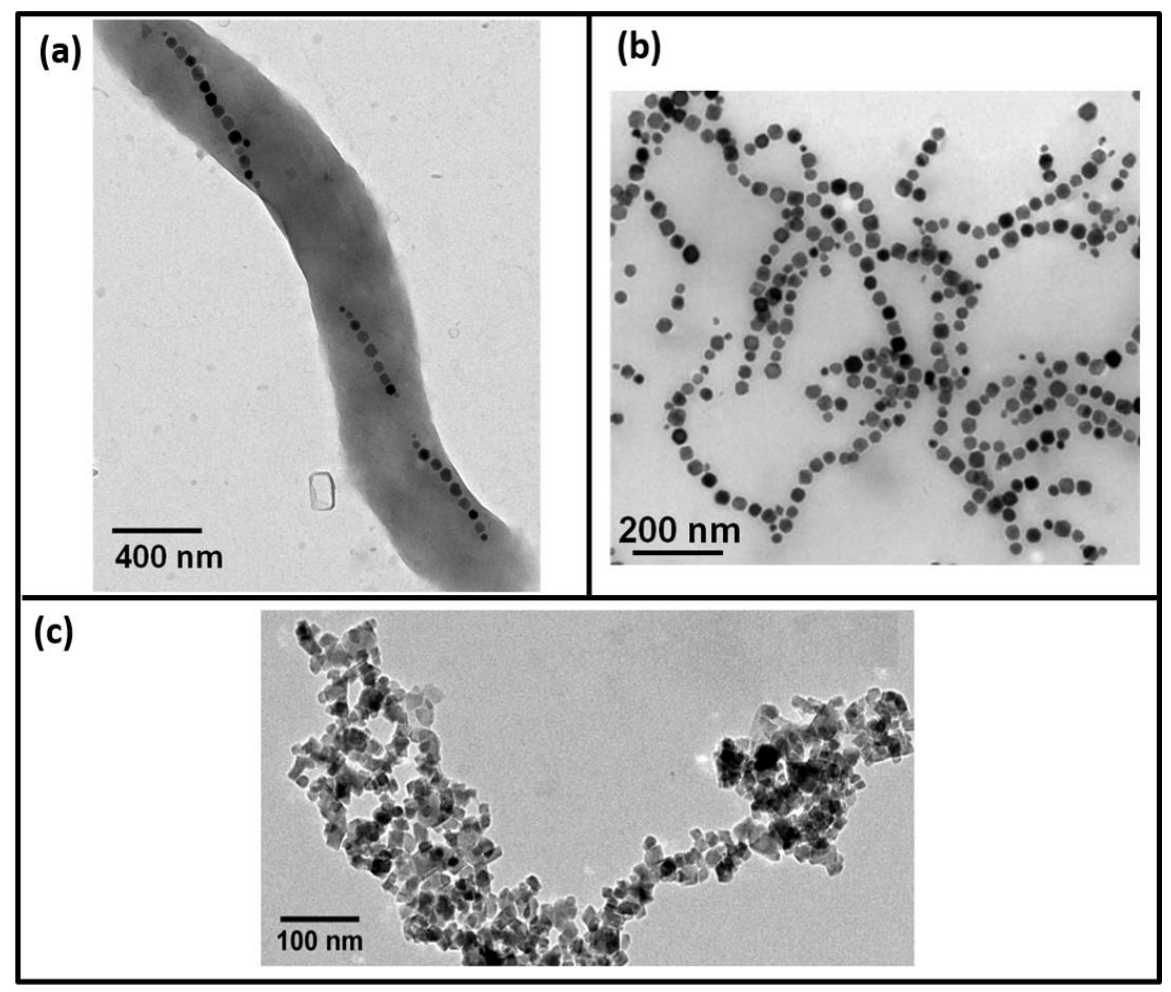


291 Figure 1: Transmission electron microscopy images of (a) an AMB-1 Magnetospirillum magnetotacticum magnetotactic

292 bacterium, (b), chains of magnetosomes extracted from magnetotactic bacteria and (c) an IONP. Seven microliter suspensions

293 containing magnetotactic bacteria, chains of magnetosomes, and IONPs were deposited and dried on top of a carbon grid

294 before TEM observation.

295 Magnetosomes are composed of a core, which is made of iron oxide, as revealed by the FT-IR Fe-O

296 peak at $580 \mathrm{~cm}^{-1}$ (table 1) and further determined to be maghemite by saturating isothermal remnant

297 magnetic measurements (47). The core is surrounded by a coating of organic material, including

298 phospholipids and lipopolysaccharides, as revealed by a series of FT-IR peaks $\left[\mathrm{C}=\mathrm{O}\right.$ at $1740 \mathrm{~cm}^{-1}$,

299 amide at $1650 \mathrm{~cm}^{-1}$, amine at $1530 \mathrm{~cm}^{-1}, \mathrm{P}=\mathrm{O}$ at $1250 \mathrm{~cm}^{-1}$, and PO at $1050 \mathrm{~cm}^{-1}$ (Table 1)]. The

300 coating, whose function is to bind magnetosomes together in chains (48), is estimated to be 1 to $5 \mathrm{~nm}$

301 thick (Figure 1(b)) and to contain 13.9\% carbon, as estimated by CHNS analysis. LAL measurements

302 further indicated that the organic material at the magnetosome surface is partially derived from

303 endotoxins whose concentration in CM suspensions is estimated as 1400-8400 EU per ml per mg of iron

304 oxide. Moreover, CM suspensions appear sufficiently stable to enable their in vivo administration, as

305 their absorption measured at $480 \mathrm{~nm}$ does not decrease by more than $30 \%$ within 20 minutes (Table 1 ).

\begin{tabular}{|c|c|c|c|c|c|c|c|c|c|c|c|c|}
\hline & \multicolumn{6}{|c|}{ CM } & \multicolumn{6}{|c|}{ IONP } \\
\hline $\begin{array}{l}\text { Endotoxin level } \\
(\mathrm{EU} / \mathrm{mg} / \mathrm{mL})\end{array}$ & \multicolumn{6}{|c|}{$1400-8400$} & \multicolumn{6}{|c|}{$<50$} \\
\hline $\begin{array}{c}\% \text { stability on water } \\
\text { (iron concentration }=1 \mathrm{mg} / \mathrm{mL} \text { ) }\end{array}$ & \multicolumn{6}{|c|}{70} & \multicolumn{6}{|c|}{100} \\
\hline Coating thickness (nm) & \multicolumn{6}{|c|}{$1-5$} & \multicolumn{6}{|c|}{1} \\
\hline Isoelectric Point (a.u) & \multicolumn{6}{|c|}{4.2} & \multicolumn{6}{|c|}{9.5} \\
\hline $\mathrm{pH}$ & 2 & 4 & 6 & 8 & 10 & 12 & 2 & 4 & 6 & 8 & 10 & 12 \\
\hline$\zeta$-Potential (mV) & 20 & 2.5 & -18 & -26 & -34 & -38 & 7 & 6 & 6 & 5 & 3 & -20 \\
\hline$\% \mathrm{C}$ & \multicolumn{6}{|c|}{13.9} & \multicolumn{6}{|c|}{8.7} \\
\hline \multirow{2}{*}{$\begin{array}{c}\text { SAR ( } 2 \mu \mathrm{LL}, 40 \mu \mathrm{g} \text { of iron) } \\
\text { (W/gFe) }\end{array}$} & \multicolumn{3}{|c|}{ Water } & \multicolumn{3}{|c|}{ Brain } & \multicolumn{3}{|c|}{ Water } & \multicolumn{3}{|c|}{ Brain } \\
\hline & \multicolumn{3}{|c|}{57} & \multicolumn{3}{|c|}{4} & \multicolumn{3}{|c|}{10} & \multicolumn{3}{|c|}{0} \\
\hline \multirow{2}{*}{$\mathrm{FT}-\mathrm{IR}\left(\mathrm{cm}^{-1}\right)$} & 580 & 1050 & 1250 & 1530 & 1650 & 1740 & \multicolumn{2}{|c|}{610} & \multicolumn{2}{|c|}{1025} & \multicolumn{2}{|c|}{1150} \\
\hline & $\mathrm{Fe}-\mathrm{O}$ & $\mathrm{P}-\mathrm{O}$ & $\mathrm{P}=0$ & $\begin{array}{c}\mathrm{N}-\mathrm{H} \\
\text { (amine) }\end{array}$ & $\begin{array}{c}\mathrm{N}-\mathrm{H} \\
\text { (amide) }\end{array}$ & $C=0$ & \multicolumn{2}{|c|}{ Fe-O } & \multicolumn{2}{|c|}{$\begin{array}{l}\mathrm{C}-\mathrm{O} \\
\text { (alcohol) }\end{array}$} & \multicolumn{2}{|c|}{$\begin{array}{l}\mathrm{C}-\mathrm{O} \\
\text { (ether) }\end{array}$} \\
\hline
\end{tabular}

307 Table 1: The endotoxin content estimated in Endotoxin units (EU per $\mathrm{mg}$ in iron per ml), percent decreased absorption

308 measured at $480 \mathrm{~nm}$ in suspensions containing $\mathrm{CM}$ and IONP at a concentration of $1 \mathrm{mg}$ in iron per ml after twenty minutes,

309 and estimates of the isoelectric point and zeta potential as a function of $\mathrm{pH}$ for suspensions containing CMs or IONPs. 

with CHNS and assignments from the different FT-IR peaks measured by FT-IR for the CM and IONP dried suspensions.

312 Estimates of the specific absorption rates (SAR) in W per gram in iron for $2 \mu 1$ containing $40 \mu \mathrm{g}$ of CMs or IONPs in iron 313 oxide mixed in water or introduced inside the mouse brains.

314 Compared with CMs, IONPs are also ferromagnetic iron oxide nanoparticles but characterized by the

315 following distinct features. Their geometric structure is parallelepipedic, they are not organized in chains 316 and tend to form small aggregates as observed in the TEM image in Figure 1(c). INOPs are made of a 317 core measuring $\sim 19 \mathrm{~nm}$ by TEM (49), and whose composition is iron oxide as determined by FT-IR 318 measurements that display an Fe-O peak at $610 \mathrm{~cm}^{-1}$ (Table 1). The IONP core is surrounded by 319 synthetic hydroxyethyl starch, as suggested by FT-IR and CHNS measurements performed on the 320 IONPs, which shows FT-IR peaks at $1150 \mathrm{~cm}^{-1}$ and $1050 \mathrm{~cm}^{-1}$ that are attributed to hydroxyethyl starch 321 ether and alcohol functional groups, and has a carbon percent of $8.7 \%$, revealing the presence of an 322 organic coating surrounding the inorganic iron oxide core (Table 1). Compared with CMs, the IONP 323 surface contains a much lower endotoxin concentration of $50 \mathrm{EU}$ per $\mathrm{ml}$ per $\mathrm{mg}$ of iron oxide, as 324 measured with the LAL assay. Furthermore, IONPs are characterized by ferrimagnetic properties at 325 physiological temperatures but at the following lower values: (1) $\mathrm{H}_{\mathrm{c}} \sim 120$ Oe and (2) $\mathrm{M}_{\mathrm{r}} / \mathrm{M}_{\mathrm{s}} \sim 0.15$ 326 (49), (Fig. S6 and Table 1), which should yield lower SAR values. Furthermore, given that they are not 327 less stable than CMs (Table 1) and that their anti-tumor efficacy has been demonstrated on tumor328 bearing mice using magnetic hyperthermia (50), IONPs appear to be good standard for comparison to 329 assess CM efficacy.

\subsection{Under AMF applications, CM can release heat and an immune-stimulating substance more} efficiently than IONPS

In an attempt to mimic the conditions in the in vivo treatments and to study the release of endotoxins

333 from the CM and IONP surfaces in these conditions, we introduced $2 \mu 1$ of suspensions containing 40

$334 \mu \mathrm{g}$ of these nanoparticles in iron oxide at the bottom of a tube that we exposed to $1,2,3$, and 4 magnetic 335 sessions during which an AMF of $198 \mathrm{kHz}$ and average strength $30 \mathrm{mT}$ was applied for 30 minutes. 336 During each of these 4 magnetic sessions, CM and IONP suspensions led to maximal temperatures 
$337\left(\mathrm{~T}_{\max }\right)$ of $57^{\circ} \mathrm{C}$ and $28^{\circ} \mathrm{C}$, respectively, after 3 minutes of AMF application (Fig. S2(a)). Specific

338 absorption rates (SAR) were deduced from the formula $\mathrm{SAR}=\mathrm{C}_{\mathrm{water}}(\Delta \mathrm{T} / \delta \mathrm{t}) / \mathrm{C}_{\mathrm{m}}$, where $\Delta \mathrm{T} / \delta \mathrm{t}$ are the

339 initial slopes of the plot in Fig. S2(a) $\left[\Delta \mathrm{T} / \delta \mathrm{t}=0.27{ }^{\circ} \mathrm{C} / \mathrm{sec}\right.$ and $0.05{ }^{\circ} \mathrm{C} / \mathrm{sec}$ for $\mathrm{CM}$ and IONP,

340 respectively], $\mathrm{C}_{\text {water }}=4.2 \mathrm{~J} / \mathrm{g} \cdot \mathrm{K}$ is the specific heat capacity of water, and $\mathrm{C}_{\mathrm{m}}=0.02 \mathrm{~g} / \mathrm{mL}$ is the

341 concentration in iron oxide of the different nanoparticle suspensions. The SARs were estimated as $57 \pm$

$3426 \mathrm{~W} / \mathrm{g}_{\mathrm{Fe}}$ and $10 \pm 3 \mathrm{~W} / \mathrm{g}_{\mathrm{Fe}}$ for CMs and IONPs, respectively. Therefore, the heating properties of CMs

343 appear far superior to those measured for IONPs.

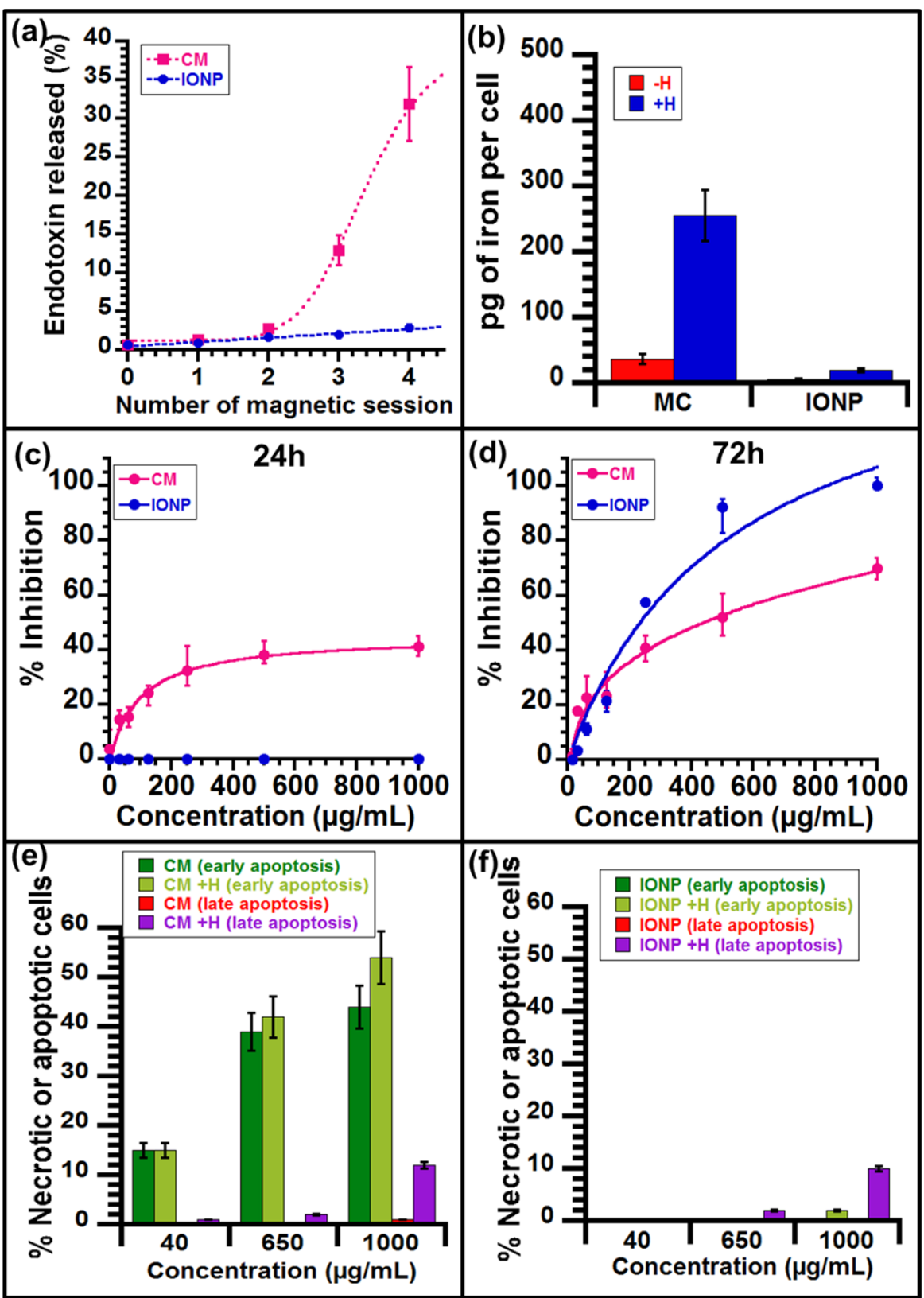


Figure 2: (a) Percentage of endotoxin release from $2 \mu$ suspensions containing $40 \mu \mathrm{g}$ of CM or IONP in iron oxide that were exposed to 1, 2, 3 or $4 \mathrm{~S}$ with an AMF of $198 \mathrm{kHz}$ and average strength of $30 \mathrm{mT}$ applied for 30 minutes. (b) The quantity of

347 iron released from MCs and IONPs, measured in pg and internalized per cell from U87-Luc cells incubated for 24 hours with

$3481 \mathrm{mg} / \mathrm{mL}$ of $\mathrm{CM}$ or IONP in maghemite with $(+\mathrm{H}) /$ without $(-\mathrm{H})$ AMF, where the AMF is the same as in (a). (c and d) The 349 percentage inhibition of cell proliferation as a function of nanoparticle concentration for CMs and IONPs in maghemite in 350 U87-Luc cells incubated for (c) 24 hours or (d) 72 hours with nanoparticle concentrations varied between $8 \mu \mathrm{g} / \mathrm{mL}$ and 1 $351 \mathrm{mg} / \mathrm{mL}$. (e and f) The percentages of late apoptotic (+ necrotic) and early apoptotic cell death as a function of nanoparticle 352 concentration with $(\mathrm{H}) /$ without(-H) AMF where the AMF is the same as in (a) in U87-Luc cells incubated for 24 hours with 353 (e) CM and (f) IONP at concentrations of $40 \mu \mathrm{g} / \mathrm{mL}, 650 \mu \mathrm{g} / \mathrm{mL}$, and $1 \mathrm{mg} / \mathrm{mL}$.

354 Moreover, the percentage of endotoxin release, which remains relatively similar at 1 to $3 \%$ during the 355 first 2 magnetic sessions, strongly increased to $11 \%$ and $32 \%$ following the third and fourth magnetic sessions, respectively (Fig. 2(a)). This indicates that endotoxins, which are initially at the magnetosome surface, are progressively released from CMs under AMF application. Using CMs exposed to AMF, it

358 therefore appears possible to simultaneously produce heat and release an immune-stimulating substance

359 such as an endotoxin. Although endotoxins cannot be used in medicinal preparations, they may be 360 replaced by a nontoxic equivalent, such as M-PLA, (51), (52). Combining the production of 361 localized heat with the release of such a substance may possibly enhance antitumor efficacy. Compared 362 with CMs, IONPs released a lower quantity of endotoxins and their percentage of endotoxin release did 363 not exceed 5\% between 1 and $4 \mathrm{~S}$ (Fig. 2(a)). Taken together, these heating and endotoxin release 364 behaviors suggest that IONPs are less promising than CMs for the magnetic hyperthermia and endotoxin 365 treatment in tumors.

\subsection{CMs induce enhanced U87-Luc early apoptotic cell death and internalization in vitro}

367 In the absence of the AMF, the cytotoxicity of CMs towards U87-Luc cells was compared with that of 368 IONPs using nanoparticle suspensions that were added to the cells and incubated for 24 and 72 hours at 369 concentrations between $40 \mu \mathrm{g} / \mathrm{mL}$ and $1 \mathrm{mg} / \mathrm{mL}$. At 24 hours, the percent inhibition of cell proliferation 370 increased with increasing nanoparticle concentrations from 0 to $40 \%$ for $\mathrm{CM}$ and remained at $0 \%$ for the 371 IONPs (Figure 2(c)). At 72 hours, the percent inhibition increased more significantly for CMs, i.e., from 
3720 to $60 \%$, than for IONPs, i.e., from 0 to $100 \%$ (Figure $2(\mathrm{~d})$ ). While CMs were observed to be more

373 cytotoxic than IONPs at 24 hours, the opposite behavior was observed at 72 hours.

374 U-87-Luc cells were also incubated for 24 hours with CMs and IONPs at three different concentrations 375 of 40,650 , and $1000 \mu \mathrm{g} / \mathrm{ml}$ and then exposed to an AMF of $198 \mathrm{kHz}$ and strength $47 \mathrm{mT}$ for the first 30

376 seconds and $30 \mathrm{mT}$ for the remaining 29.5 minutes in an attempt to reach $41{ }^{\circ} \mathrm{C}$, a temperature above 377 which mild hyperthermia conditions are expected to occur (30). The 40 and $650 \mu \mathrm{g} / \mathrm{ml}$ concentrations

378 led to temperature increases of less than $2{ }^{\circ} \mathrm{C}$, which were insufficient to reach the hyperthermia 379 conditions. These concentrations resulted in necrosis and late apoptosis percentages that remained below $380 \sim 4 \%$ with/without AFM for the CMs and IONPs and early apoptosis percentages that were similar 381 with/without $\mathrm{AFM}$ at $\sim 15 \%$ and $\sim 40 \%$ for $\mathrm{CMs}$ at 40 and $650 \mu \mathrm{g} / \mathrm{ml}$ in iron oxide, respectively, and at $3820 \%$ for IONPs (Figs. 2(e) and 2(f)). In contrast, at a concentration of $1 \mathrm{mg} / \mathrm{ml}$, both CMs and IONPs 383 yielded a more significant temperature increase of $7^{\circ} \mathrm{C}$ up to $41^{\circ} \mathrm{C}$ (Fig. S2(b)), which resulted in an 384 increase in the necrotic and late apoptotic cell death percentages by $10 \%$. These in vitro heating 385 behaviors are In contrast, with those observed in solution, where CMs were observed to heat much more 386 than IONPs.

387 The mechanisms of cellular death induced by CMs and IONPs were further examined. CMs appear to 388 induce cellular death mainly through early apoptosis, with a percentage of early apoptotic cell death that 389 increased with increasing $\mathrm{CM}$ concentrations from $15 \%$ at $40 \mu \mathrm{g} / \mathrm{ml}$ to $50 \%$ at $1 \mathrm{mg} / \mathrm{ml}$. Similar 390 percentages were observed for CMs with/without AMF (Fig. 2(e)); this cell death mechanism was not 391 observed with IONPs (Fig. 2(f)).

392 The differences in cell death mechanisms observed for IONPs and CMs as well as the more pronounced 393 decrease in heating efficacy for CMs than IONPs observed between the in vitro and in suspension 394 heating conditions may be explained by the different internalization properties. Indeed, the quantity of 395 iron released from the nanoparticles, which are internalized in each cell, increased from 36.8 and $5.5 \mathrm{pg}$ 396 per cell without AMF application to 255.7 and 19.8 pg per cell with AMF application for the CMs and 397 IONPs, respectively. It therefore appears that CMs are internalized better than IONPs and that the 
398 internalization is enhanced by the presence of the AMF for both types of nanoparticles. This

399 enhancement is more pronounced for CMs than for IONP by factors of 7 and 4, respectively (Figure 400 2(b)). The different internalization properties for the CMs and IONPs may be explained by differences 401 in their charges, i.e., $\mathrm{CM}$ and IONP are negatively and positively charged at physiological $\mathrm{pH}$, 402 respectively (Table 1)); differences in organization, i.e., CM and IONP are well-dispersed and tend to 403 aggregate, respectively; and to larger values of coercivity for CMs (200-300 Oe) compared to IONPs 404 (120 Oe) that may enhance CM magnetic field coupling. Furthermore, CM organization in chains may 405 favor internalization by groups containing several magnetosomes $(30)$, i.e., potentially 6 for chains 406 averaging $250 \mathrm{~nm}$ in length (Fig. S1(b), while IONPs may result in nanoparticles being internalized one 407 by one or at a lower rate. The enhanced internalization of CMs may favor early apoptosis, which was 408 previously observed with iron oxide nanoparticles, (53), and reduce its heating properties, possibly by 409 preventing nanoparticle Brownian heating mechanisms (54).

\subsection{CMs promote enhanced antitumor efficacy towards intracranial U87-Luc glioblastoma}

411 In the in vivo studies, mice receive the following treatment at the center of intracranial U87-Luc tumors:

412 (1) glucose followed by treatment or not with magnetic sessions (groups 1 and 2), (2) $40 \mu \mathrm{g}$ of CMs or 413 IONPs in maghemite without any further treatment (groups 3 and 6), (3) $40 \mu \mathrm{g}$ of CMs in maghemite 414 followed by 15 magnetic sessions (groups 4 and 5), or (4) $40 \mu \mathrm{g}$ of IONPs in maghemite followed by 12 415 magnetic sessions (group 7). The average size of the treated tumors was $3-5 \mathrm{~mm}^{3}$, except in group 5 416 where it was $25 \mathrm{~mm}^{3}$. Following injection, the mice were exposed to 12 to 15 magnetic sessions, during 417 which an AMF of $198 \mathrm{kHz}$ and strength $30 \mathrm{mT}$ was applied for 30 minutes (see Table S1(a) for a 418 summary of the treatment conditions). In this study, U87 cells were labeled with the firefly luciferase 419 gene to evaluate the changes in tumor volumes following the treatments via tumor bioluminescence 420 intensity (BLI) measurements using the relationship between BLI and tumor volumes that we 421 established (Fig. S3) (40), (42), (43), (44). For the mice belonging to the different groups without 422 any measurable production of heat (groups 1, 2, 3, 6, and 7), Figures 3(a) to 3(e) show that the tumor 423 volumes increased following tumor cell implantation without any signs of antitumor activity. Mice 
424 belonging to these groups were rapidly euthanized between days 28 and 42, leading to a rather low

425 median survival time of 42 to 46 days. In contrast, in the mice belonging to groups with heated tumors

426 (groups 4 and 5), antitumor activity is clearly observed and is more pronounced in the small (group 4)

427 than in the large (group 5) treated tumors.

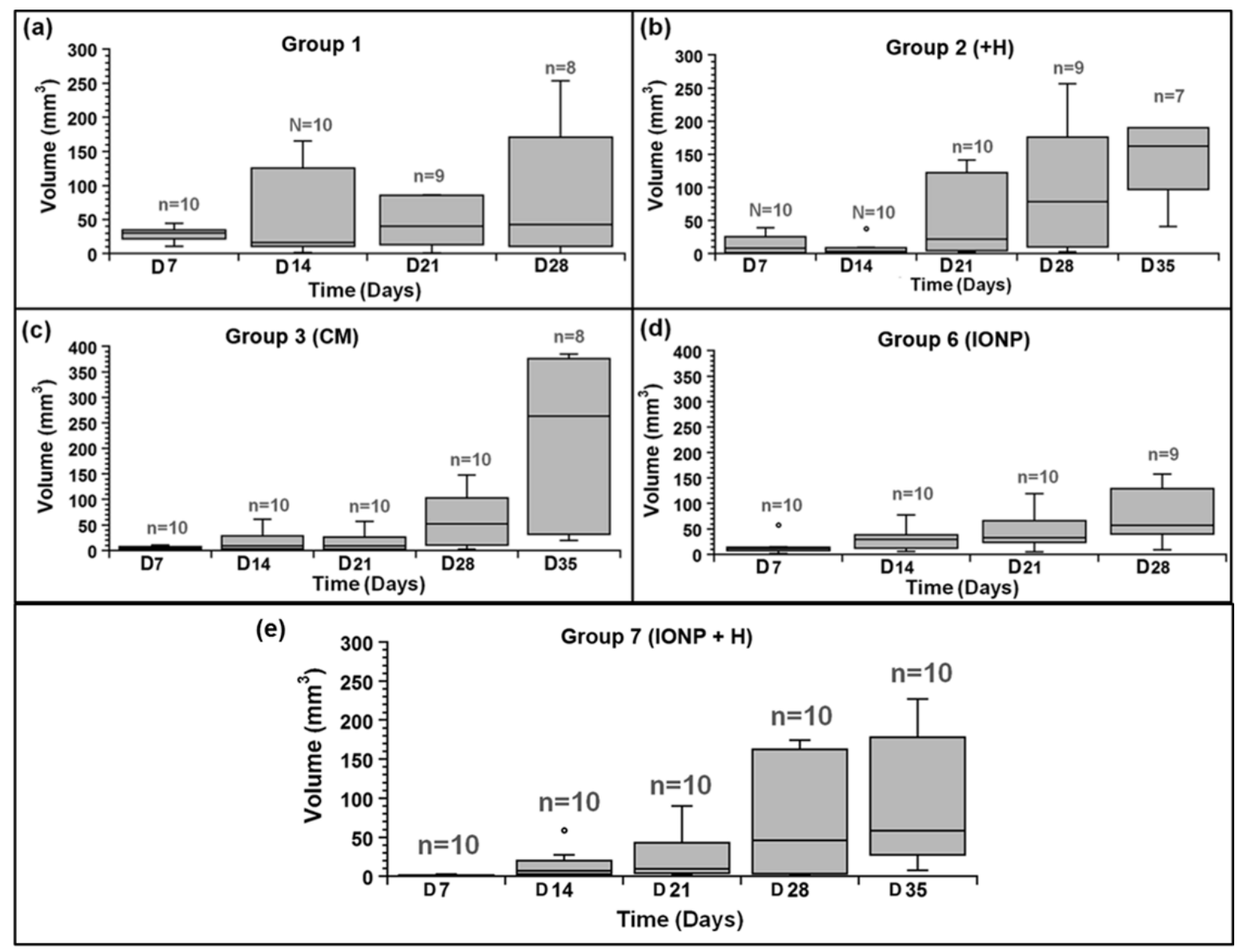

429 Figure 3: Variations in tumor volumes as a function of time during the days following U87-Luc tumor cell implantation at 430 D0 for (a) untreated mice (group 1), (b) mice exposed to 15 magnetic sessions (group 2, $+\mathrm{H}$ ), mice receiving a suspension 431 containing either (c) $40 \mu \mathrm{g}$ of CMs in iron oxide at the site of tumor cell implantation (group 3) or $40 \mu \mathrm{g}$ of IONPs in iron 432 oxide (group 6, IONP), or (e) $40 \mu \mathrm{g}$ of IONPs in iron oxide and exposed to 15 magnetic sessions. These variations are plotted 433 using Tukey diagrams, where error bars designate the maximum and minimum tumor volume values, circles represent single 434 tumor values, lower and upper horizontal rectangular sides designate lower and upper quartiles, respectively, and horizontal 435 lines within each box plot represents median tumor volumes. The number of living mice used to draw each box plot (n) is 436 also indicated above each box plot. 
437 Figures 4(a) shows that tumor growth is delayed in group 5 with a median tumor volume that first

438 decreases from $25 \mathrm{~mm}^{3}$ at day 7 to $5 \mathrm{~mm}^{3}$ at day 14 and then increases from $5 \mathrm{~mm}^{3}$ at day 14 to $70 \mathrm{~mm}^{3}$

439 at day 42. The behavior of a typical mouse belonging to this group is shown in Figure 4(b), which shows

440 three tumor volume oscillations (decrease followed by increase). This suggests that AMF application

441 causes repetitive anti-tumor activity without preventing tumor regrowth after 15 magnetic sessions. This

442 therapy led to a survival time of 49 days, which is only slightly increased compared to the unheated 443 groups.

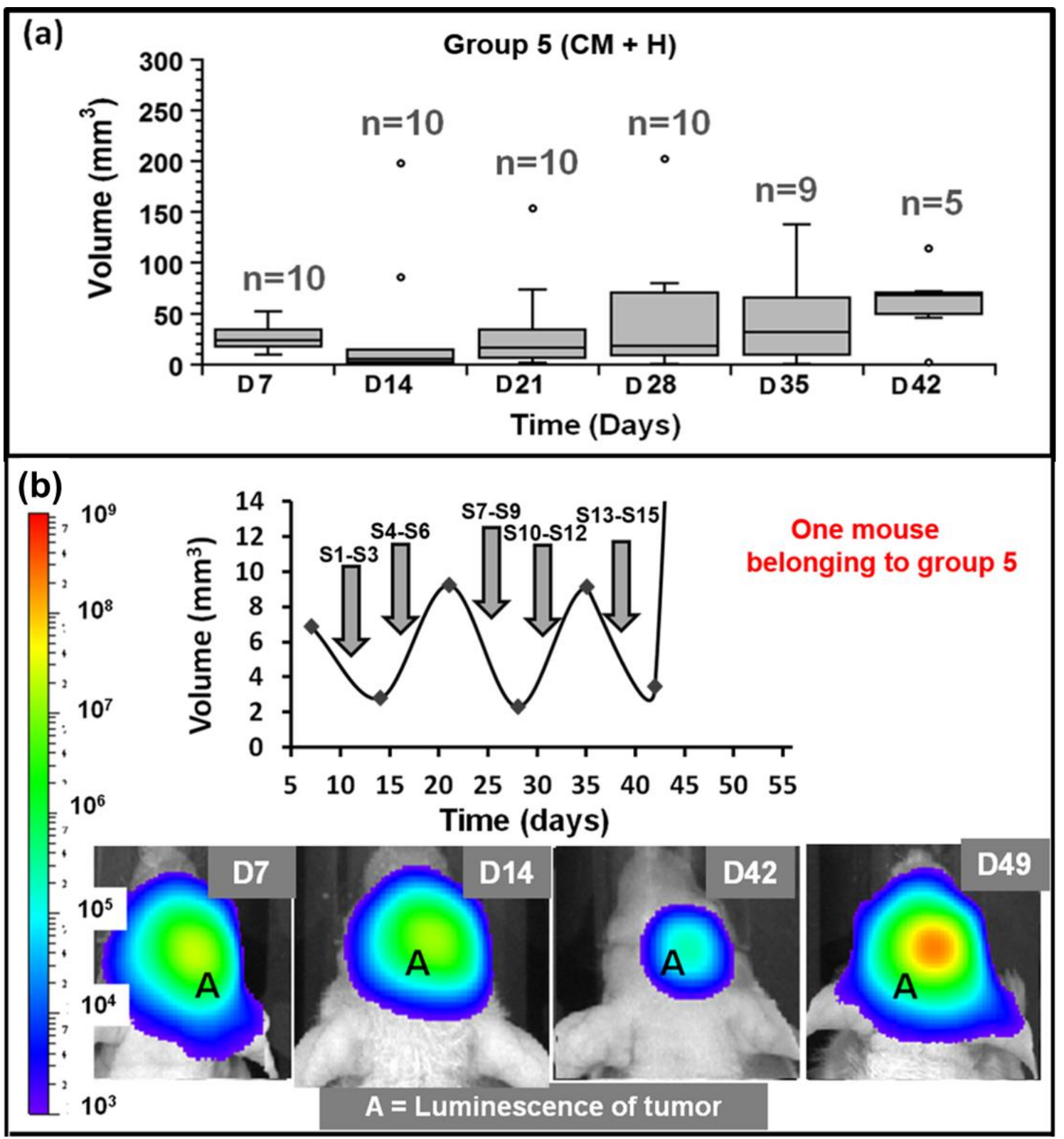


445 Figure 4: (a) Variations in tumor volumes as a function of time during the days following U87-Luc tumor cell implantation at

446 D0 for mice receiving a suspension containing $40 \mu \mathrm{g}$ of CMs in iron oxide. The tumors reach an average volume of 25 mm ${ }^{3}$

447 at D7 and were treated with 15 magnetic sessions (group 5, CM+H). (b) Variations in tumor volume and bioluminescence

448 intensity as a function of time during the days following tumor cell implantation in a mouse in group 5 with a tumor volume at

449 D7 of $\sim 7.5 \mathrm{~mm}^{3}$ that received $40 \mu \mathrm{g}$ of a suspension of CMs in iron oxide on D7 followed by 15 magnetic sessions (S1 to 450 S15).

451 Figure 5(a) shows more significant antitumor activity in group 4 with full tumor disappearance at day 35 452 without tumor regrowth following 1 to 15 magnetic sessions. For a typical mouse belonging to this 453 group, Figure 5(b) shows the gradual decrease in the tumor volume following 1 to 15 magnetic sessions 454 until full tumor disappearance at day 40 without tumor regrowth. Compared with the unheated groups, 455 group 4 had the highest survival at 90 days $(\mathrm{p}$-value $<0.0001)$.

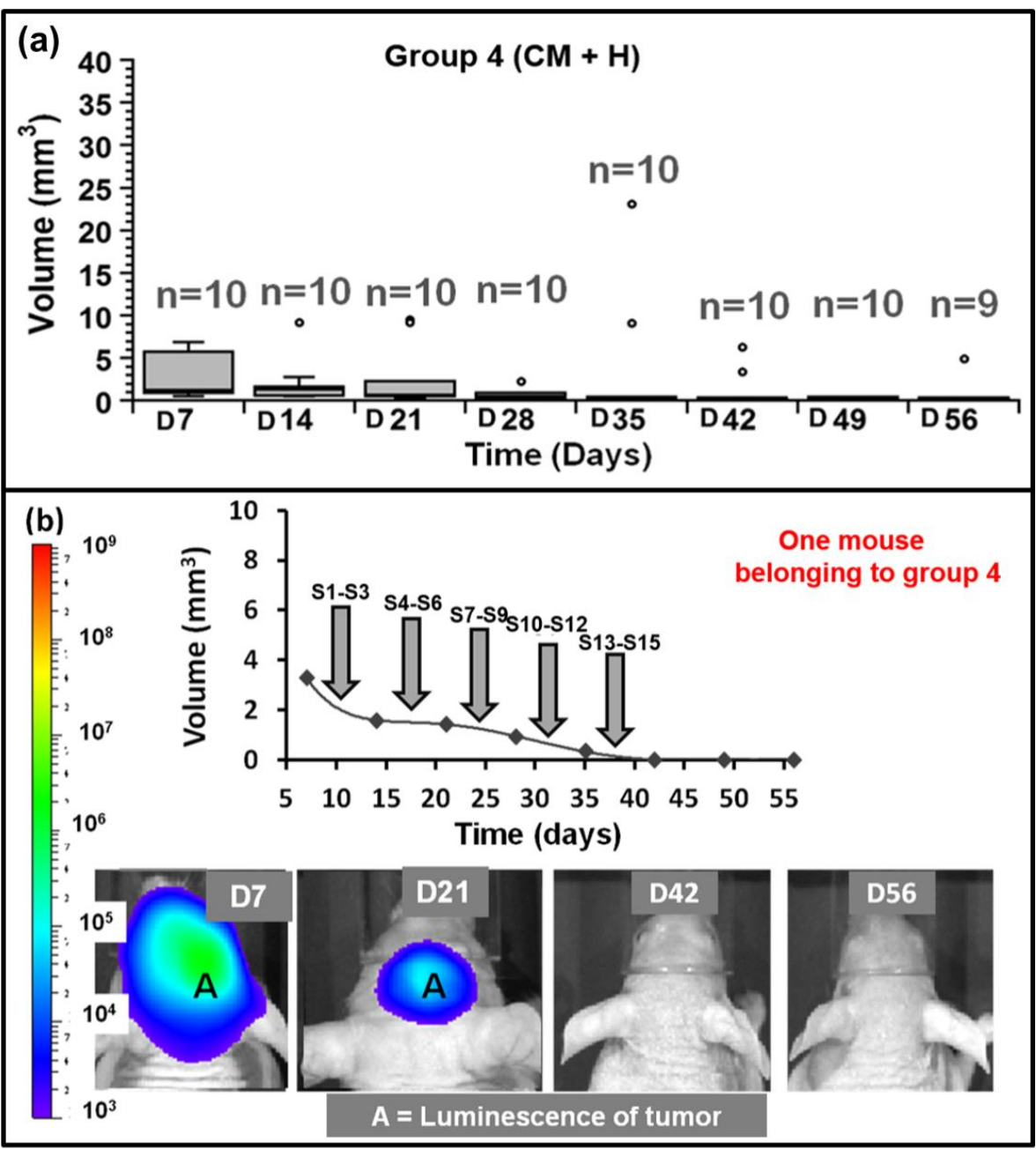


457 Figure 5: (a) Variations in tumor volumes as a function of time during the days following U87-Luc tumor cell implantation at 458 D0 for mice receiving a suspension containing $40 \mu \mathrm{g}$ of CMs in iron oxide when the tumors reach an average volume of 3 $459 \mathrm{~mm}^{3}$ at $\mathrm{D} 7$ followed by 15 magnetic sessions (group 4, $\mathrm{CM}+\mathrm{H}$ ). (b) Variations in tumor volume and bioluminescence 460 intensity as a function of time during the days following tumor cell implantation for a mouse belonging to group 4 with a 461 tumor volume at D7 of $\sim 3 \mathrm{~mm}^{3}$ that receiving $40 \mu \mathrm{g}$ of CMs in iron oxide on D7 followed by 15 magnetic sessions (S1 to $462 \mathrm{~S} 15)$

463 On day $150,40 \%$ of the mice from this group were still alive without any unusual behaviors. Then, the 464 mice were euthanized and slides of their brains from the tumor cell implantation region were imaged by 465 optical microscopy, revealing the absence of tumors or tumor lesions and a brain neuronal structure 466 identical to that of a healthy brain (Figure 6). These results suggest that the tumors had fully disappeared 467 in these mice. Further analysis of mice from group 4 suggests that treatment does not result in any 468 healthy tissue damage. Indeed, it can be deduced from the optical microscopy images of the brain 469 sections from mice treated with $\mathrm{CM}$ with/without AMF collected at different times ranging from 4 hours 470 to 150 days after CM administration (Figs. S4(a) to S4(d), S5(a) to S5(d) and Figs. 8(a) to 8(g), 9(a) to $4719(\mathrm{~d})$ ) that healthy tissues in the hippocampus and brain do not contain lesions or edema. Such 472 observations can be explained by an LPS-activated neuro-protective response by the microglia (55) . 473 Thus, the treatment of the mice in group 4 appears safe and fully efficient. 


\section{Brain fully cured}

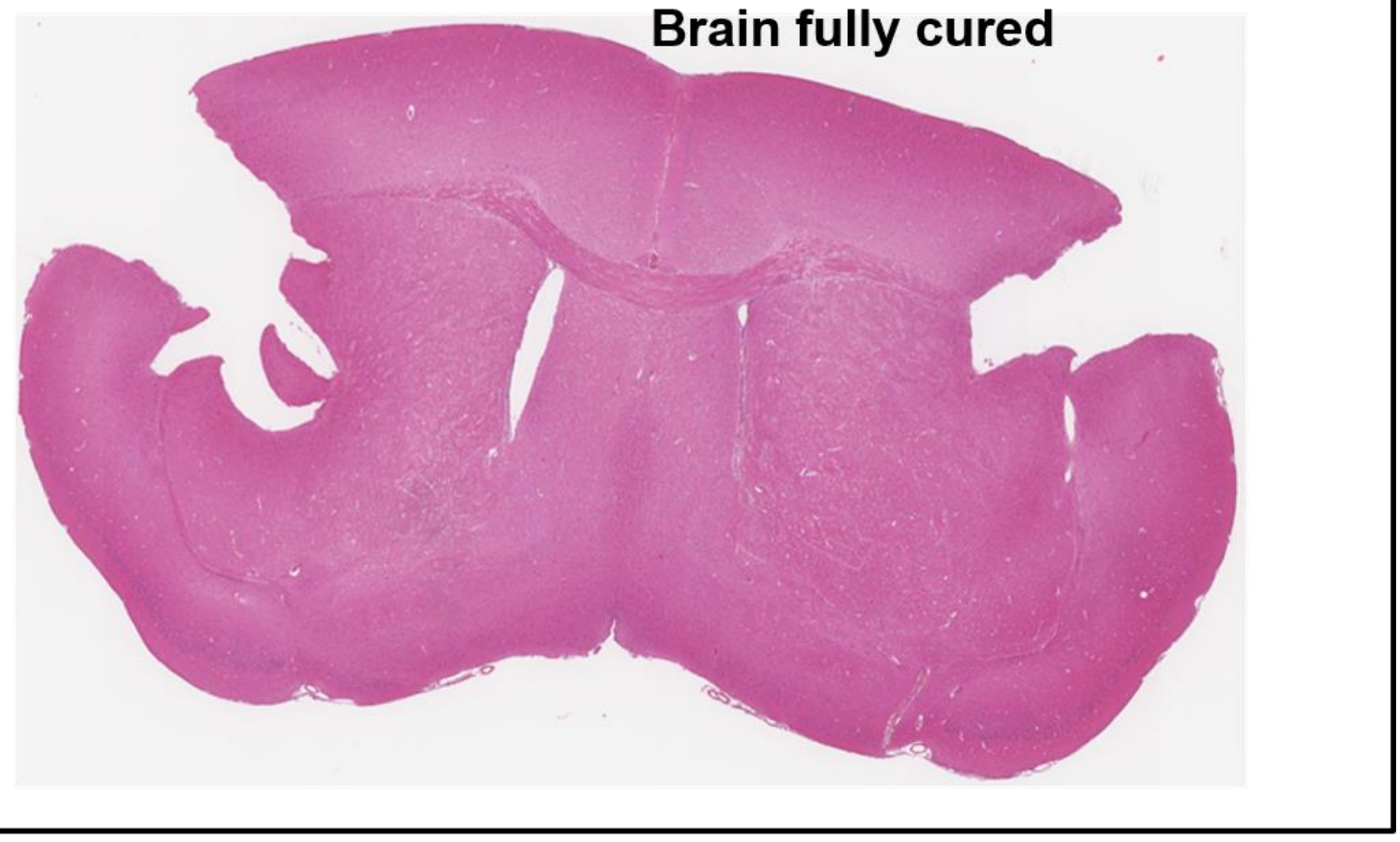

475 Figure 6: Optical microscopy image of a 4- $\mu$ m-thick brain section stained with hematoeosin from a mouse in group 4 that

476 received $40 \mu \mathrm{g}$ of $\mathrm{CMs}$ in iron oxide followed by 15 magnetic sessions. This mouse was euthanized 7 months after 477 magnetosome administration. No tumor was observed in this brain section.

$480 \mathrm{CM}$ led to temperature increases of $4{ }^{\circ} \mathrm{C}$ at D8 (S1), $1.7^{\circ} \mathrm{C}$ at D9 (S2), $0.4{ }^{\circ} \mathrm{C}$ at D10, D15 and D16 (S3,

481 S4, S5) and then constant temperatures after D17 (Figures. 7(a) and 7(b)). 

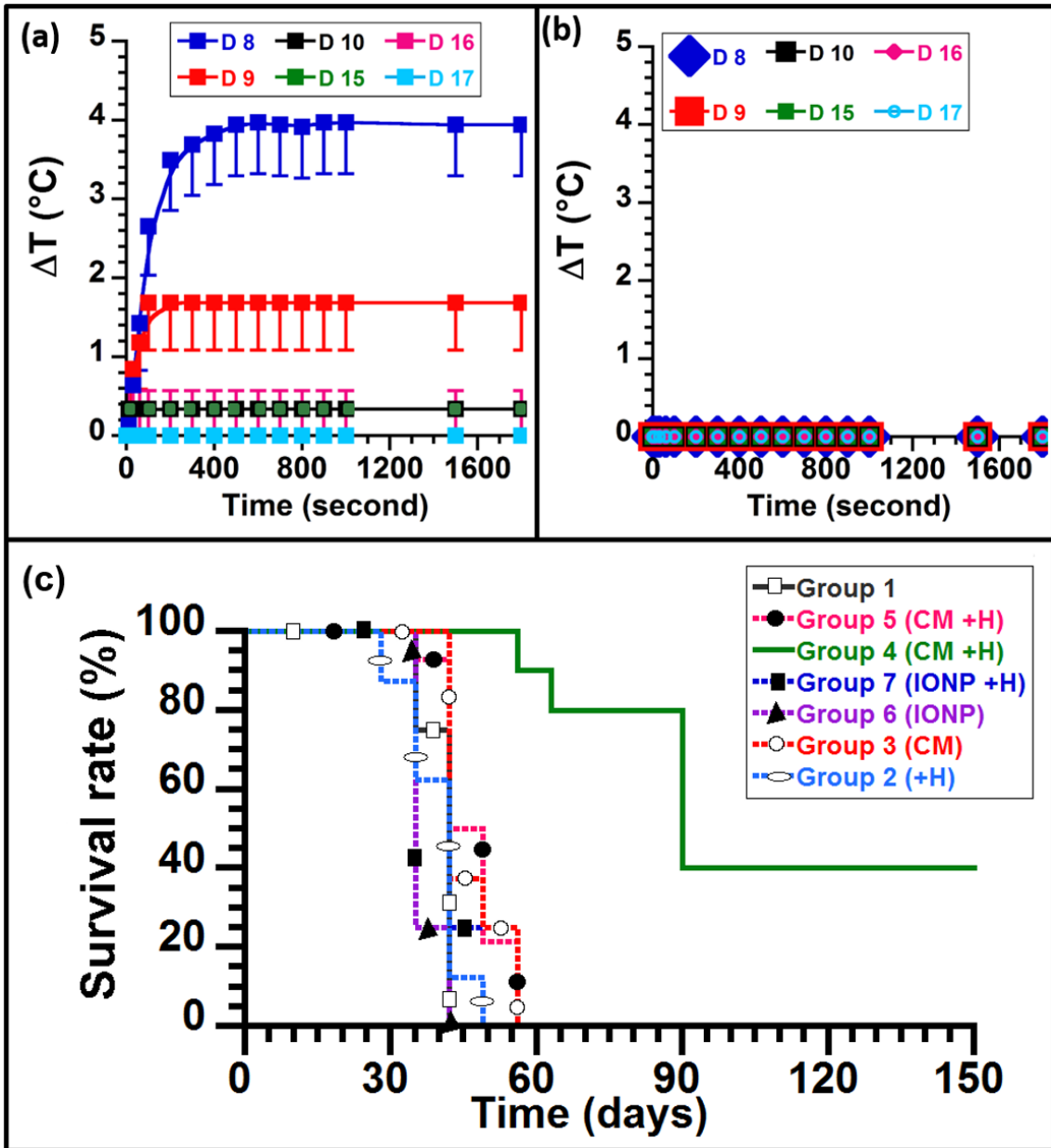

483 Figure 7: (a), Temperature increases above $28.5^{\circ} \mathrm{C}$ observed during each magnetic session $(\Delta \mathrm{T})$ on D8, D9, D10, D15, D16 484 and D17 in the mice from groups 4 and 5 treated with CMs. (b) The same as in (a) for the mice in group 7 treated with 485 IONPs. After D17, tumor temperature increases were no longer observed. (c)Variations in mouse survival times as a function 486 of time during the days following U87-Luc tumor cell implantation for mice with the following treatments: (1) untreated 487 (group 1), (2) exposed to 15 magnetic sessions (group 2), (3) treated with suspensions containing $40 \mu \mathrm{g}$ of CMs in iron oxide 488 without magnetic sessions (group 3), (4) treated with $40 \mu \mathrm{g}$ of CMs in iron oxide in $\sim 3 \mathrm{~mm}^{3}$ tumors followed by 15 magnetic 489 sessions (group 4), (5) administered $40 \mu \mathrm{g}$ of CMs in iron oxide in $25 \mathrm{~mm}^{3}$ tumors followed by 15 magnetic sessions (group 490 5), (6) administered $40 \mu \mathrm{g}$ of IONPs in iron oxide (group 6), and administered $40 \mu \mathrm{g}$ of IONPs in iron oxide followed by 15 491 magnetic sessions (group 7).

492 The rather limited increases in temperature under AMF, which are less pronounced than in the 493 capillaries (Fig. S2(a)), may be explained by the effects of AMF on CM distribution. Indeed, the tumor 494 occupation percentage decreases from 50\% right after CM administration without AMF at D8 (Figs. 495 9(a) and 9(b)) down to 8-15\% on D8 and D11 after 1 and 3 magnetic sessions, respectively, (Figs. 8(a), 
496 8(b) and 8(d)). There percentages were estimated by delineating the regions containing the CMs and the

497 tumors and by measuring the ratio between the surfaces of these two regions. Moreover, the decrease in

498 CM heating properties over time may be attributed to internalization of CMs in U87 tumor cells, which 499 was observed at 24 hours after 3 magnetic sessions (Fig 8(d) and 8(e)).

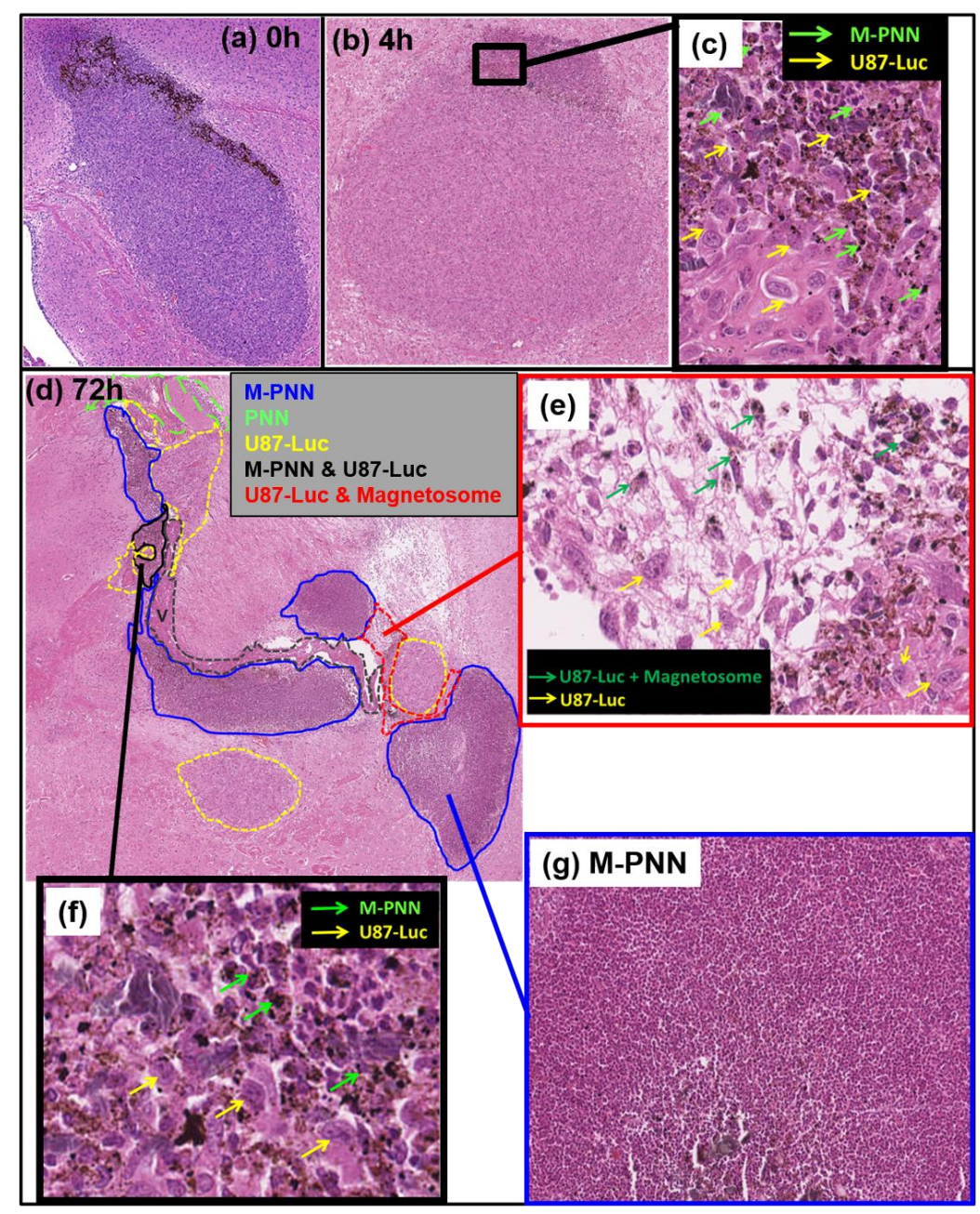

$501 \quad$ Figure 8: Optical microscopy images of $4 \mu \mathrm{m}$ thick brain sections stained with hematoeosin from mice receiving $40 \mu \mathrm{g}$ of

502 CMs in iron oxide and exposed to (a-c) one or (d-g) three magnetic sessions. The mice were euthanized (a) 0 hours $(0 \mathrm{~h})$, (b

503 and c) 4 hours $(4 \mathrm{~h})$, or (d-g) 72 hours $(72 \mathrm{~h})$ after MC administration with either (a-c) one or (d-g) three magnetic sessions.

504 (c) An enlargement of the region in (b). The red arrows in (c) designate polynuclear neutrophils. (e), (f), and (g) are

505 enlargements of three different regions from (d). PNN, M-PNN, U87-Luc, M-PNN \& U87-Luc, and U87-Luc \&

506 magnetosomes designate polynuclear neutrophils, magnetosomes colocalized with polynuclear neutrophils, U87-Luc cells,

507 magnetosomes colocalized with polynuclear neutrophils and U87-Luc cells, and U87-Luc cells colocalized with

508 magnetosomes, respectively. The regions containing these different cells are surrounded in (d), while individual cells are

509 indicated by arrows in (c), (e) and (f). 
510 In contrast with CMs, IONPs do not produce any heat in vivo under the same excitation conditions. This

511 behavior can be explained by their lower concentration in the tumor under AMF applications, i.e., they

512 are observed at the tumor surface as well as part of the tumor periphery at 6 hours (Figs. S4(a) and

$513 \mathrm{~S} 4(\mathrm{c}))$; their more rapid diffusion in the ventricles, i.e., IONPs and CMs localize in the ventricles at 6

514 and 72 hours, respectively, (Figs. S4(a) and S4(b), Figs. 8(d)); and their earlier internalization in tumor

515 U87-Luc and healthy BETZ brain cells, i.e., IONPs and CMs are internalized at 6 and 72 hours,

516 respectively, (Figs. S4(c) and S4(d), Fig. 8(e)). The combination of a low concentration in the tumor

517 together with rather low SAR may undermine the IONPs' heating power, as was observed in vivo.

518 3.6. CM exposed to AMF activate PNN, which are possibly involved in antitumor activities

519 Previous studies have reported that immune cells, such as dendritic cells, natural killers, and B and T

520 cells, may participate in tumor destruction following hyperthermia treatment (56). Here, we examined

521 potential involvement of other types of immune cells, i.e., polynuclear neutrophils (PNN), which have

522 only rarely been associated with antitumor activities (57), (58). While PNNs were not detected after

523 glucose (Fig. S5) or IONP (Fig. S4) administration with/without magnetic sessions, we observed that

524 these cells were localized at the same sites as the magnetosomes, forming a complex designated M-PNN

525 in the mouse euthanized 4 hours after CM administration with/without magnetic sessions (Figs. 8(b),

$5268(\mathrm{c}), 8(\mathrm{~d}), 8(\mathrm{f}), 8(\mathrm{~g}), 9(\mathrm{a})$ and 9(c)). More precisely, M-PNNs designate assemblies of magnetosomes

527 and PNNs where the magnetosomes are less than $1 \mu \mathrm{m}$ away from the PNNs. The number of M-PNNs

528 was estimated as 14000-19000 per $\mathrm{mm}^{2} 4$ hours after CM administration (Table S2). Because PNNs are

529 known to be recruited by endotoxins (59), this behavior could be attributed to the endotoxins

530 surrounding the magnetosome mineral core that attract PNN. Seventy-two hours later, the M-PNNs had

531 disappeared in the absence of AMF (Figs. 9(b) and 9(d) and Table S2) but were detected in large

532 quantities of 27,500 per $\mathrm{mm}^{2}$ (Table S2) after 3 magnetic sessions either within the tumor periphery

533 (Fig. 8(d) and 8(f)) or in the tumor (Figs. 8(d) and 8(e)). 

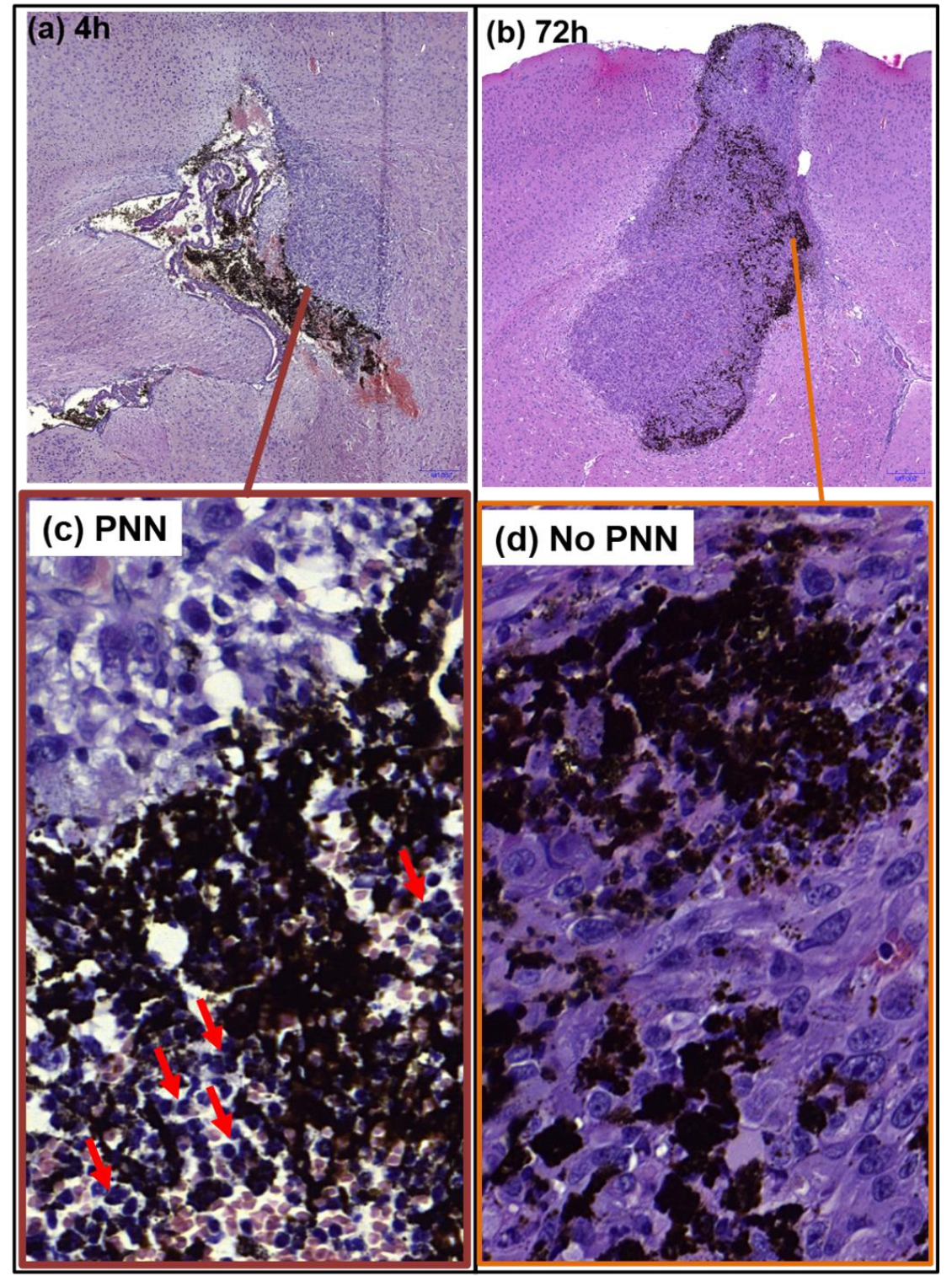

535 Figure 9: Optical microscopy images of $4 \mu \mathrm{m}$ thick brain sections stained with hematoeosin from mice receiving $40 \mu \mathrm{g}$ of

536 CMs in iron oxide without magnetic sessions and euthanized (a) 4 hours (4 h) or (b) 72 hours (72 h) after magnetosome

537 administration. (c) and (d) are enlargements of two regions in (a) and (b), respectively. PNN are observed in (c) and indicated 538 by red arrows, but not in (d).

539 These interesting behaviors might suggest that in the absence of AMF, endotoxins are progressively

540 deactivated, perhaps due to magnetosome internalization followed by magnetosome and endotoxin

541 decomposition. However, in the presence of AMF, the endotoxins are re-activated, possibly through the

542 release of endotoxins from the magnetosome surface, a behavior that perfectly fits with the observations

543 in solution (Fig. 2(a)) and/or via the destruction of cells in which magnetosomes are initially internalized

544 before AMF application. M-PNN complexes may have two main functions. First, they may be involved 
545 in tumor destruction, as they are observed in the tumor region and Toll-like receptor (TLR) from the

546 treated mice could be activated and trigger antitumor activity; this was previously reported for mice

547 bearing B16 tumors (60). Second, they may also be involved in magnetosome capture and re-

548 distribution. Indeed, after one and three magnetic sessions, magnetosomes and PNNs alone are rarely

549 observed in the entire brain, including the tumor regions (Figs. 7(b) and 7(d)), and M-PNNs appear to be

550 located either in the tumor, near the tumor periphery or in the ventricles (Figs. 7(b) and 7(c)). These

551 results suggest that PNNs progressively migrate in the region where the magnetosomes are located

552 between 0 and 4 hours after CM administration to form M-PNN complexes and that these complexes

553 carry the magnetosomes from the inside to the outside of the tumor, possibly through the ventricle blood

554 vessels. This behavior further agrees with the absence of heat production after D17, which suggests that

555 magnetosomes have left the tumor by this date and/or have been dissolved into free iron. This idea is

556 also in line with the well-known function of PNNs, which is to remove bacterial residues (61), (62).

557 Magnetosome progressive departure from the tumor, possibly followed by magnetosome redistribution

558 within the mouse, could be appealing for the treatment by preventing crystallized magnetosomes from

559 remain in the brain for too long a period of time. Optimum treatment conditions correspond to those

560 where magnetosomes remain in the brain long enough to perform the treatment, but not for too long, to

561 avoid unnecessary long-term magnetosome interactions with brain tissues. These conditions may be

562 identified by controlling PNN activation and M-PNN complex formation under AMF application.

563 3.7. CMs appear to destroy glioblastoma tumors more efficiently than chemically synthesized $564 \quad$ nanoparticles under AMF applications

565 Using the same quantity of nanoparticles administered, we have shown in this study that CMs lead to

$56640 \%$ of mice with full tumor disappearance, while IONPs do not yield any observable antitumor

567 activities. This result agrees with previous animal studies performed on mice and rats bearing GBM

568 using intratumor administration of chemically synthesized nanoparticles exposed to AMF that did not

569 improve survival (63) or increased survival by 15 days without resulting in a full cure (64), (26). In

570 addition to being more efficient, magnetosomes could also be used in a lower quantity, thus 
571 strengthening treatment safety. Indeed, the quantity of magnetosomes necessary to eradicate U87-Luc

572 GBM in this study, which was 1 to $13 \mu \mathrm{g}$ in maghemite per $\mathrm{mm}^{3}$ of tumor volume, is much less than 60

$573 \mu \mathrm{g}$ per $\mathrm{mm}^{3}$ of tumor volume, which produced less-efficient anti-tumor activities with chemically 574 synthesized nanoparticles (9).

\section{4. CONCLUSION}

576 We demonstrated that $40 \%$ of mice bearing intracranial U87-Luc tumors displayed full tumor 577 disappearance after intratumor administration of $40 \mu \mathrm{g}$ of CMs followed by 12 to 15 magnetic sessions, 578 during which an AMF of average strength $30 \mathrm{mT}$ and frequency $198 \mathrm{kHz}$ was applied for 30 minutes. In 579 contrast, similar antitumor efficacy was not observed when mice were treated with the same conditions

580 and administered chemically synthesized nanoparticles instead of magnetosomes. Furthermore, the 581 absence of mouse brain damage during and following the various treatments appears to indicate that a 582 safe treatment could be performed with magnetosomes, provided that the endotoxins are replaced with 583 an equivalently active but nonpyrogenic substance such as M-PLA. Antitumor activity does not appear 584 to be dominated by nanoparticle cytotoxicity, as the CMs, which are more efficient than IONPs in vivo, 585 do not enhance cytotoxicity towards U87-Luc cells compared with IONPs. Moreover, nanoparticle 586 administration without AMF does not produce any observable anti-tumor effects. Instead, tumor 587 destruction appears to be due to the heat produced by the CMs under AMF application, as the only mice 588 that displayed clear anti-tumor effects had their tumors heated (groups 4 and 5). Under heating 589 conditions, tumor tissue destruction may be caused by irreversible cell damage; cytolysis; actin filament, 590 microtubule or mitochondrial dysfunction; DNA replication or RNA synthesis inhibition; or DNA 591 polymerase denaturation (65), but these mechanisms seem insufficient to fully explain the observed 592 antitumor activities. Indeed, tumor destruction does occur when the magnetosomes occupy a small 593 percentage of the total tumor volume $(\sim 10 \%)$, suggesting that magnetosomes occupying the tumor can 594 induce the destruction of the entire tumor. We have identified the following three possible mechanisms 595 that could be responsible for full tumor destruction: 
596 i) Early apoptosis, as apoptotic cell death is observed to be dominant in vitro for CMs and heat was

597 previously shown to favor apoptotic cell death $(65),(66),(67)$;

598 ii) Microvascular damage due to the presence of magnetosomes in the ventricles that possibly leads

599 to the destruction of the blood vessels supplying the tumor with oxygen, which was previously reported

600 to occur during hyperthermia, (68), and could possibly occur because CMs were observed in the

601 ventricles near the blood vessel; and

602 iii) the involvement of PNN, which were previously reported to be involved in antitumor activity, 603 (58) and were attracted by the magnetosomes in the tumor region due to the presence of endotoxins at 604 magnetosome surface.

605 Finally, our study also suggests a method to control magnetosome distribution by attracting PNNs to the 606 magnetosome region, which promotes the formation of magnetosome/PNN complexes that may 607 progressively remove magnetosomes from the tumor through the ventricle blood vessels and enable their 608 elimination. This process appears to be governed by the application (or not) of an AMF.

\section{ACKNOWLEDGMENTS}

610 We would like to thank the Eurostars Program (Nanoneck-2, E9309), subvention AIR from the region of 611 Paris (A1401025Q), the ANRT, the ANR (Méfisto project), the French Research Tax Credit Program,

612 Paris Biotech Santé, BPI, the University Paris 6, the University Paris XI, Marianne Labussière and Elvis 613 Dervishi, as well as all other people and structures in France and Europe that have helped us and been 614 supportive and enthusiastic about our research activities.

\section{Abbreviations}

616 GBM glioblastoma

617 AMF alternating magnetic field

618 IONP iron oxide nanoparticles

$619 \mathrm{CM}$ magnetosome chains 
620 UV irradiation of an ultraviolet lamp

621 LAL limulus amebocyte lysate

622 DMEM Dulbecco's Modified Eagle Medium

623 FBS fetal bovine serum

624 HBSS Hank's Balanced Salt Solution

$625 \mathrm{~S} \quad$ magnetic sessions

626 BLI bioluminescence intensity

627 H\&E hematoxylin-eosin

628 PNN polynuclear neutrophils

629 SAR specific absorption rates

630 TLR toll like receptor

631 M-PNN PNN were localized at the same site as magnetosomes

632 REFERENCES

633 1. E. Alphandéry, P. Grand-Dewyse, R. Lefèvre, C. Mandawala, M. Durand-Dubief, Cancer

634 therapy using nanoformulated substances: scientific, regulatory and financial aspects. Expert Review of 635 Anticancer Therapy. 15 (2015) 1233-55.

636 2. D.P. O'Neal, L.R. Hirsch, N.J. Halas, J.D. Payne, J.L. West, Photo-thermal tumor ablation in 637 mice using near infrared-absorbing nanoparticles. Cancer Letters. 209 (2004) 171-6.

638 3. I.H. El-Sayed, X. Huang, M.A. El-Sayed, Selective laser photo-thermal therapy of epithelial 639 carcinoma using anti-EGFR antibody conjugated gold nanoparticles. Cancer Lett. 239 (2006) 129-35.

640 4. X.Y. Su, P.D. Liu, H. Wu, N. Gu, Enhancement of radiosensitization by metal-based 641 nanoparticles in cancer radiation therapy. Cancer Biol Med. 11 (2014) 86-91.

642 5. S. Her, D.A. Jaffray, C. Allen, Gold nanoparticles for applications in cancer radiotherapy: 643 Mechanisms and recent advancements. Advanced Drug Delivery Reviews. (2015) in Press 644 http://dx.doi.org/10.1016/j.addr.2015.12.012. 
645 6. O.K. Kosheleva, T.C. Lai, N.G. Chen, M. Hsiao, C.H. Chen, Selective killing of cancer cells by 646 nanoparticle-assisted ultrasound. Journal of Nanobiotechnology. (2016) 14:46.

647 7. Y. You, Z. Wang, H. Ran, Y. Zheng, D. Wang, J. Xu, and al, Nanoparticle-enhanced synergistic 648 HIFU ablation and transarterial chemoembolization for efficient cancer therapy. Nanoscale 8 (2016) $6494324-39$.

650 8. M. Bañobre-López, A. Teijeiro, J. Rivas, Magnetic nanoparticle-based hyperthermia for cancer 651 treatment. Reports of Practical Oncology \& Radiotherapy 18 (2013) 397-400.

652 9. A. Jordan, R. Scholz, K. Maier-Hauff, F.K.H.V. Landeghem, N. Waldoefner, U. Teichgraeber, 653 and al, The effect of thermotherapy using magnetic nanoparticles on rat malignant glioma. J 654 Neurooncol. 78 (2005) 7-14.

655 10. J.A. Schwartzbaum, J.L. Fisher, K.D. Aldape, M. Wrensch, Epidemiology and molecular 656 pathology of glioma. Nature Clinical Practice Neurology 2 (2006) 494-503.

657 11. UK CR. Types of primary brain tumors. Last accessed 13 August 2009 at 658 http://www.cancerhelp.org.uk/help/default.asp?page=5014

659 12. Q.T. Ostrom, L. Bauchet, F.G. Davis, I. Deltour, J.L. Fisher, C.E. Langer, and al, The 660 epidemiology of glioma in adults: a "state of the science" review. Neuro Oncol. 16 (2014) 896-913.

661 13. R. Stupp, M.E. Hegi, W.P. Mason, M.J. van den Bent, M.J. Taphoorn, R.C. Janzer, and al, 662 Effects of radiotherapy with concomitant and adjuvant temozolomide versus radiotherapy alone on 663 survival in glioblastoma in a randomised phase III study: 5-year analysis of the EORTC-NCIC trial. The 664 Lancet Oncology 10 (2009) 459-66.

665 14. C. Billecke, S. Finniss, L. Tahash, C. Miller, T. Mikkelsen, N.P. Farrell, and al., Polynuclear 666 platinum anticancer drugs are more potent than cisplatin and induce cell cycle arrest in glioma. Neuro667 oncol 8 (2006) 215-26. 
668 15. H.H. Ross, M. Rahman, L.H. Levkoff, S. Millette, T. Martin-Carreras, E.M. Dunbar, and al.,

669 Ethynyldeoxyuridine (EdU) suppresses in vitro population expansion and in vivo tumor progression of 670 human glioblastoma cells. J Neurooncol. 105 (2011) 485-98.

671 16. F-Y. Yang, M-C. Teng, M. Lu, H-F. Liang, Y-R. Lee, C-C. Yen, and al., Treating glioblastoma 672 multiforme with selective high-dose liposomal doxorubicin chemotherapy induced by repeated focused 673 ultrasound. Int J Nanomedicine 7(2012) 965-74.

674 17. F. Safdie, S. Brandhorst, M. Wei, W. Wang, C. Lee, S. Hwang, and al., Fasting Enhances the 675 Response of Glioma to Chemo- and Radiotherapy. PLOS ONE 7 (2012) e44603.

676 18. G.L. Bidwell, E. Perkins, J. Hughes, M. Khan, J.R. James, D. Raucher, Thermally Targeted 677 Delivery of a c-Myc Inhibitory Polypeptide Inhibits Tumor Progression and Extends Survival in a Rat 678 Glioma Model. PLOS ONE 8. (2013) e55104.

679 19. W.L. Titsworth, G.J.A. Murad, B.L. Hoh, M. Rahman, Fighting Fire with Fire: The Revival of 680 Thermotherapy for Gliomas. Anticancer Res. 34 (2014) 565-74.

681 20. F. Jiang, X. Zhang, S.N. Kalkanis, Z. Zhang, H. Yang, M. Katakowski, and al., Combination 682 Therapy with Antiangiogenic Treatment and Photodynamic Therapy for the Nude Mouse Bearing U87 683 Glioblastoma. Photochem Photobiol. 84 (2008) 128-37.

684 21. I. Rabias, D. Tsitrouli, E. Karakosta, T. Kehagias, G. Diamantopoulos, M. Fardis, and al., Rapid 685 magnetic heating treatment by highly charged maghemite nanoparticles on Wistar rats exocranial glioma 686 tumors at microliter volume. Biomicrofluidics. 4 (2010) 024111.

687 22. M. Shinkai, M. Yanase, M. Suzuki, H. Honda, T. Wakabayashi, J. Yoshida, and al., Intracellular 688 hyperthermia for cancer using magnetite cationic liposomes. Journal of Magnetism and Magnetic 689 Materials. 194 (1999) 176-84. 
23. A. Ito, M. Shinkai, H. Honda, T. Kobayashi, Heat-inducible TNF-alpha gene therapy combined

691 with hyperthermia using magnetic nanoparticles as a novel tumor-targeted therapy. Cancer Gene Ther. 8 692 (2001) 649-54.

693 24. T. Ohno, T. Wakabayashi, A. Takemura, J. Yoshida, A. Ito, M. Shinkai, and al., Effective 694 Solitary Hyperthermia Treatment of Malignant Glioma Using Stick Type CMC-magnetite. In vivo 695 Study. J Neurooncol. 56 (2002) 233-9.

696 25. B. Le, M. Shinkai, T. Kitade, H. Honda, J. Yoshida, T. Wakabayashi, and al., Preparation of 697 Tumor-Specific Magnetoliposomes and Their Application for Hyperthermia. Journal of Chemical 698 Engineering of Japan. 34 (2001) 66-72.

699 26. K. Maier-Hauff, R. Rothe, R. Scholz, U. Gneveckow, P. Wust, B. Thiesen, and al., Intracranial 700 thermotherapy using magnetic nanoparticles combined with external beam radiotherapy: results of a 701 feasibility study on patients with glioblastoma multiforme. J Neurooncol. 81 (2007) 53-60.

702 27. K. Maier-Hauff, F. Ulrich, D. Nestler, H. Niehoff, P. Wust, B. Thiesen, and al., Efficacy and 703 safety of intratumoral thermotherapy using magnetic iron-oxide nanoparticles combined with external 704 beam radiotherapy on patients with recurrent glioblastoma multiforme. J Neurooncol. 103 (2011) 31770524.

706 28. E. Alphandéry, S. Faure, O. Seksek, F. Guyot, I. Chebbi, Chains of Magnetosomes Extracted 707 from AMB-1 Magnetotactic Bacteria for Application in Alternative Magnetic Field Cancer Therapy. 708 ACS Nano. 5 (2011) 6279-96.

709 29. E. Alphandéry, F. Guyot, I. Chebbi, Preparation of chains of magnetosomes, isolated from 710 Magnetospirillum magneticum strain AMB-1 magnetotactic bacteria, yielding efficient treatment of 711 tumors using magnetic hyperthermia. International Journal of Pharmaceutics. 434 (2012) 444-52. 
712 30. E. Alphandéry, M. Amor, F. Guyot, I. Chebbi, The effect of iron-chelating agents on

713 Magnetospirillum magneticum strain AMB-1: Stimulated growth and magnetosome production and

714 improved magnetosome heating properties. Applied Microbiology and Biotechnology. 96 663-70.

715 31. E. Alphandéry, S. Faure, L. Raison, E. Duguet, P.A. Howse, D.A. Bazylinski, Heat Production

716 by Bacterial Magnetosomes Exposed to an Oscillating Magnetic Field. J Phys Chem C. 115 (2011) 1871722.

718 32. E. Alphandéry, I. Chebbi, F. Guyot, M. Durand-Dubief, Use of bacterial magnetosomes in the 719 magnetic hyperthermia treatment of tumours: A review. International Journal of Hyperthermia. 29 $720 \quad$ (2013) 801-9.

721 33. E. Alphandéry, Applications of Magnetosomes Synthesized by Magnetotactic Bacteria in 722 Medicine. Front Bioeng Biotechnol. 11 (2014) 2:5.

723 34. D.E. Bordelon, C. Cornejo, C. Grüttner, F. Westphal, T.L. DeWeese, R. Ivkov, Magnetic 724 nanoparticle heating efficiency reveals magneto-structural differences when characterized with wide 725 ranging and high amplitude alternating magnetic fields. Journal of Applied Physics. 109 (2011) 124904.

726 35. C. Grüttner, K. Müller, J. Teller, F. Westphal, A. Foreman, R. Ivkov, Synthesis and antibody 727 conjugation of magnetic nanoparticles with improved specific power absorption rates for alternating 728 magnetic field cancer therapy. Journal of Magnetism and Magnetic Materials. 311 (2007) 181-6.

729 36. K. Cui, X. Xu, H. Zhao, S.T.C. Wong, A quantitative study of factors affecting in vivo 730 bioluminescence imaging. Luminescence. 23 (2008) 292-5.

731 37. A. Sun, L. Hou, T. Prugpichailers, J. Dunkel, M.A. Kalani, X. Chen, and al., Firefly luciferase732 based dynamic bioluminescence imaging: a noninvasive technique to assess tumor angiogenesis. 733 Neurosurgery. 66 (2010) 751-757. 
734 38. R. Hashizume, T. Ozawa, E.B. Dinca, A. Banerjee, M.D. Prados, C.D. James, and al., A human

735 brainstem glioma xenograft model enabled for bioluminescence imaging. J Neurooncol. 96 (2010) 1517369.

737 39. E.B. Dinca, J.N. Sarkaria, M.A. Schroeder, B.L. Carlson, R. Voicu, N. Gupta, and al., 738 Bioluminescence monitoring of intracranial glioblastoma xenograft: response to primary and salvage 739 temozolomide therapy. J Neurosurg. 107 (2007) 610-6.

740 40. O. Szentirmai, C.H. Baker, N. Lin, S. Szucs, M. Takahashi, S. Kiryu, and al., Noninvasive 741 Bioluminescence Imaging of Luciferase Expressing Intracranial U87 Xenografts: Correlation with 742 Magnetic Resonance Imaging Determined Tumor Volume and Longitudinal Use in Assessing Tumor 743 Growth and Antiangiogenic Treatment Effect. Neurosurgery. 58 (2006) 365-372.

744 41. H. Zhou, K. Luby-Phelps, B.E. Mickey, A.A. Habib, R.P. Mason, D. Zhao, Dynamic Near745 Infrared Optical Imaging of 2-Deoxyglucose Uptake by Intracranial Glioma of Athymic Mice. PLOS 746 ONE. 4 (2009) e8051.

747 42. D.F. Heitjan, A. Manni, R.J. Santen, Statistical analysis of in vivo tumor growth experiments. 748 Cancer Res. 53 (1993) 6042-50.

749 43. S-J. Kim, H.J. Lee, M.S. Kim, H.J. Choi, J. He, Q. Wu, et al., Macitentan, a Dual Endothelin 750 Receptor Antagonist, in Combination with Temozolomide Leads to Glioblastoma Regression and Long751 term Survival in Mice. Clin Cancer Res. 21 (2015) 4630-41.

752 44. E. Alphandéry, A.T. Ngo, C. Lefèvre, I. Lisiecki, L.F. Wu, M.P. Pileni. Difference between the 753 Magnetic Properties of the Magnetotactic Bacteria and Those of the Extracted Magnetosomes: Influence 754 of the Distance between the Chains of Magnetosomes. J Phys Chem C. 112 (2008) 12304-9.

755 45. D.A. Bazylinski, R.B. Frankel, Magnetosome formation in prokaryotes. Nat Rev Micro. 2 (2004) $756 \quad 217-30$. 
757 46. L.C. Branquinho, M.S. Carrião, A.S. Costa, N. Zufelato, M.H. Sousa, R. Miotto, and al., Effect

758 of magnetic dipolar interactions on nanoparticle heating efficiency: Implications for cancer 759 hyperthermia. Scientific Reports. 3 (2013) 2887.

760 47. C. Grüttner, K. Müller, J. Teller, F. Westphal, A. Foreman, R. Ivkov, Synthesis and antibody 761 conjugation of magnetic nanoparticles with improved specific power absorption rates for alternating 762 magnetic field cancer therapy. Journal of Magnetism and Magnetic Materials. 311 (2007) 181-6.

763 48. C.R. Casella, T.C. Mitchell, Putting endotoxin to work for us: monophosphoryl lipid A as a safe 764 and effective vaccine adjuvant. Cell Mol Life Sci. 65 (2008) 3231-40.

765 49. M.E. Astiz, E.C. Rackow, J.G. Still, S.T. Howell, A. Cato, K.B. Von Eschen, and al., 766 Pretreatment of normal humans with monophosphoryl lipid A induces tolerance to endotoxin: a 767 prospective, double-blind, randomized, controlled trial. Crit Care Med. 23 (1995) 9-17.

768 50. Y. Liu, J. Wang, Effects of DMSA-Coated Fe3O4 Nanoparticles on the Transcription of Genes 769 Related to Iron and Osmosis Homeostasis. Toxicol Sci. 131 (2013) 521-36.

770 51. A. Tomitaka, Y. Takemura, Measurement of Specific Loss Power from Intracellular Magnetic 771 Nanoparticles for Hyperthermia. J Personali NanoMedicine. 1 (2015) 33-37.

772 52. D.A. Bazylinski, R.B. Frankel, Magnetosome formation in prokaryotes. Nat Rev Micro. 2 (2004) $773 \quad 217-30$.

774 53. M. Creixell, A.C. Bohórquez, M. Torres-Lugo, C. Rinaldi, EGFR-Targeted Magnetic 775 Nanoparticle Heaters Kill Cancer Cells without a Perceptible Temperature Rise. ACS Nano. 5 (2011) $776 \quad 7124-9$.

777 54. Z. Chen, W. Jalabi, K.B. Shpargel, K.T. Farabaugh, R. Dutta, X. Yin, and al., 778 Lipopolysaccharide-Induced Microglial Activation and Neuroprotection against Experimental Brain 779 Injury Is Independent of Hematogenous TLR4. J Neurosci. 32 (2012) 11706-15. 
780 55. T. Mentzel, L.F. Brown, H.F. Dvorak, C. Kuhnen, K.J. Stiller, D. Katenkamp, and al., The

781 association between tumor progression and vascularity in myxofibrosarcoma and myxoid/round cell 782 liposarcoma. Virchows Arch. 438 (2001) 13-22.

783 56. L. Asín, G.F. Goya, A. Tres, M.R. Ibarra, Induced cell toxicity originates dendritic cell death 784 following magnetic hyperthermia treatment. Cell Death Dis. 4 (2013) e596.

785 57. F. Eriksson, P. Tsagozis, K. Lundberg, R. Parsa, S.M. Mangsbo, M.A.A. Persson, and al., 786 Tumor-Specific Bacteriophages Induce Tumor Destruction through Activation of Tumor-Associated 787 Macrophages. J Immunol. 182 (2009) 3105-11.

788 58. J. Liang, Y. Piao, L. Holmes, G.N. Fuller, V. Henry, N. Tiao, and al., Neutrophils Promote the 789 Malignant Glioma Phenotype through S100A4. Clinical Cancer Research. 20 (2014) 187-98.

$790 \quad$ 59. A.W. Segal, How Neutrophils Kill Microbes. Annu Rev Immunol. 23 (2005) 197-223.

791 60. A.C. Silva, T.R. Oliveira, J.B. Mamani, S.M. Malheiros, L. Malavolta, L.F. Pavon, and al., 792 Application of hyperthermia induced by superparamagnetic iron oxide nanoparticles in glioma 793 treatment. Int J Nanomedicine. 6 (2011) 591-603.

794 61. A. Jordan, R. Scholz, K. Maier-Hauff, F.K.H.V. Landeghem, N. Waldoefner, U. Teichgraeber, 795 and al., The effect of thermotherapy using magnetic nanoparticles on rat malignant glioma. J 796 Neurooncol. 78 (2006) 7-14.

797 62. K.F. Chu, D.E. Dupuy, Thermal ablation of tumours: biological mechanisms and advances in 798 therapy. Nat Rev Cancer. 14 (2014) 199-208.

799 63. D.C. Wang, Y. Zhang, H.Y. Chen, X.L. Li, L.J. Qin, Y.J. Li, H.Y. Zhang, S. Wang, 800 Hyperthermia Promotes Apoptosis and Suppresses Invasion in C6 Rat Glioma Cells. Asian Pacific 801 Journal of Cancer Prevention. 13 (2012) 3239-45. 
802 64. A. Morlé, C. Garrido, O. Micheau, Hyperthermia restores apoptosis induced by death receptors 803 through aggregation-induced c-FLIP cytosolic depletion. Cell Death Dis. 6 (2015) e1633.

804 65. M. Nikfarjam, V. Muralidharan, C. Christophi, Mechanisms of Focal Heat Destruction of Liver 805 Tumors. Journal of Surgical Research. 127 (2005) 208-23. 